\title{
Perspective
}

PERSPECTIVE Actualité en histoire de l'art

1 | 2012

Art et pouvoir

\section{Art et pouvoir au Mexique : loyautés et divergences}

Art and power in Mexico: loyalties and divergences

Kunst und Macht in Mexiko: Zwischen Loyalität und Divergenz

Arte e potere in Messico: lealtà e divergenze

Arte y poder en México: lealtades y discrepancias

\section{Rita Eder}

Traducteur : Vanessa Capieu

\section{(2) OpenEdition}

Journals

Édition électronique

URL : http://journals.openedition.org/perspective/586

DOI : $10.4000 /$ perspective.586

ISSN : 2269-7721

Éditeur

Institut national d'histoire de l'art

Édition imprimée

Date de publication : 30 juin 2012

Pagination : 136-158

ISSN : 1777-7852

Référence électronique

Rita Eder, «Art et pouvoir au Mexique : loyautés et divergences », Perspective [En ligne], 1 | 2012, mis en ligne le 30 décembre 2013, consulté le 02 octobre 2020. URL : http://journals.openedition.org/ perspective/586 ; DOI : https://doi.org/10.4000/perspective.586 


\title{
Art et pouvoir au Mexique : loyautés et divergences
}

\author{
Rita Eder
}

Après la guerre de 1810-1821 à l'issue de laquelle le Mexique gagna son indépendance du royaume d'Espagne, le concept de nation et la question de sa relation avec les représentations artistiques sont apparus dans ce pays. Dès ses origines au XIX ${ }^{e}$ siècle, l'histoire de l'art mexicaine participa à construire une identité nationale au service d'un État fort. Dans les années 1980, la pensée de Benedict Anderson et d'autres auteurs comme Ernest Gellner (ANDERSON, 1983 ; GELLNER, 1988) a conduit à réévaluer le concept de nation comme une entité indissolublement liée à un pouvoir centralisé, avec pour résultat le bouleversement de l'écriture critique en histoire et en histoire de l'art et le développement, dans certains cas, des théories postcoloniales, au Mexique comme ailleurs. La nation est désormais entendue comme une combinaison d'imaginaires et de constructions idéologiques, ces dernières formant un ensemble de croyances, de valeurs et de techniques de représentation par lesquelles les classes en conflit tentent de neutraliser l'histoire de l'autre. Il est donc évident que la question nationale ne peut pas être traitée aujourd'hui comme une conception fixe, d'autant plus que les facteurs qui relient les habitants à un territoire donné aux frontières artificiellement établies sont difficiles à déterminer.

Étant donné les rapports de force entre les pays faibles et les pays puissants - en termes de technologie de guerre, de capital financier et d'appareils médiatiques -, il est même difficile de croire en l'existence d'États autonomes (HABERMAS, 1974). Dans le domaine des arts, cela fragilise encore l'idée de nation et suscite d'autres dynamiques, dans la mesure où les entités appelées "nations " sont contraintes de trouver leur place dans un contexte de mondialisation. Les diverses façons dont les nations se sont constituées, et les manières dont elles ont aidé et utilisé les arts pour forger une identité nationale, attestent la puissance des images et la polyvalence de ses signifiés : on ne peut en faire l'économie lorsqu'on aborde ce vaste sujet de l'art et du pouvoir.

Dans certains cas, l'écriture des histoires nationales peut être caractérisée par une mystification de l'Antiquité ou du passé qui, en établissant des continuités historiques, rend possible l'émergence d'une identité nationale utile à l'image de l'État. Toutefois, les grands récits historiques ont tendance à privilégier et à véhiculer des idéologies déjà bien ancrées. Observer les oppositions, les discontinuités et les différences, au contraire, permet d'accéder à une compréhension plus précise de l'art et de ses relations au pouvoir, de construire une histoire et des méthodes plus mobiles qui privilégient le passage du particulier au général et incitent à une diversité des discours. Ainsi, la New Social History of Art de T. J. Clark, selon laquelle les images sont considérées pour leur aspect visuel et non pour leur contexte historique (CLARK, 1975), le New Historicism développé par Catherine Gallagher et Stephen

Rita Eder est chercheur et professeur à I'Instituto de Investigaciones Estéticas UNAM à Mexico, dont elle a été la directrice de 1990 à 1998. Spécialiste d'art contemporain et d'historiographie, elle a écrit de nombreux ouvrages, dont Tiempo de fractura: El arte contemporáneo en el Museo de Arte Moderno de México durante la gestión de Helen Escobedo (1982-1984) (Mexico, 2010). 
Greenblatt, par lequel les petites histoires peuvent fonder une version plus complexe de la grande Histoire (GALLAGHER, GREENBLATT, 2000), la lecture critique des grands récits de Jean-François Lyotard (LYOTARD, [1979] 1984) et la notion de "petits récits " de Barthes sont autant de modèles méthodologiques opératoires pour réfléchir aux relations entre l'art et le pouvoir. De même, la discontinuité telle qu'elle a été théorisée au cinéma est également très utile pour rompre avec les discours officiels, car elle permet de dépasser le récit historique continu au profit de juxtapositions et de disjonctions qui mettent en lumière toute sa complexité.

Cette approche éclatée se prête à l'étude de l'histoire des rapports entre l'art et le pouvoir au Mexique, en la déclinant elle-même sous différentes facettes, parfois inattendues. Ce thème est fondamental dans l'histoire de l'art mexicaine, qui remonte aux débuts au $\mathrm{XIX}^{\mathrm{e}}$ siècle avec la protection du patrimoine national et se consolide par la suite avec la collaboration des arts à la fabrication d'une histoire nationale. Les conditions du pouvoir politique, depuis les années 1880, la Révolution mexicaine de 1910 et ses suites, sont celles d'un État moderne centralisé. Celui-ci est concurrencé aujourd'hui par le pouvoir parallèle des barons de la drogue, qui contribue à la déconstruction des idéologies de ce pouvoir centralisé, et qui suscite des positions critiques de la part d'artistes et de conservateurs. La situation actuelle du pays a en effet donné lieu à de nouvelles orientations dans le domaine artistique. Actuellement, alors que l'État a encore recours à des modes de représentation traditionnels, comme la commande architecturale, les artistes se penchent de manière critique sur des faits sociaux ou sur la domination évidente du capital financier. En proposant l'analyse de médias artistiques et visuels produits au Mexique (peinture, architecture, sculpture monumentale, imagerie populaire, installations...) à différents moments de son histoire contemporaine, cet article entend saisir la diversité kaléidoscopique des formes et des thèmes conçus ou perçus par le prisme du lien entre art et pouvoir.

\section{L'histoire de l'art mexicaine aux prises de la politique}

L'idée de nation moderne est intimement liée au Mexique à la conception particulière du libéralisme politique mexicain ${ }^{1}$ qui a dominé sous différentes formes dès les premières décennies du XIX ${ }^{e}$ siècle et jusqu'à récemment. Dans son étude sur le nationalisme et le libéralisme mexicain, David Brading montre que l'éducation et les arts furent des armes fondamentales pour réussir la transition vers ce système politique. Les libéraux transformèrent en effet l'Académie, fondée au XVIII siècle, en École des Beaux-Arts, et un grand nombre de concours furent mis en place afin de stimuler une peinture d'histoire capable de produire les images dont avait besoin cette nouvelle nation, qui se transforma lorsqu'apparut un pouvoir central fort, capable d'unifier les parties. Par la suite, malgré la Révolution de 1910, le libéralisme a survécu et s'est même consolidé. Il a servi de base pour justifier le pouvoir tout en faisant appel à l'identité nationale dans les domaines des arts et des sciences sociales autour desquelles s'est construite une partie de l'histoire de l'art au Mexique.

La discipline trouva son point de départ lors de la guerre de 1848 entre le Mexique et les États-Unis, qui a fait craindre le pire pour le destin du patrimoine national et a marqué le début d'une classification des œuvres d'art ainsi que leur inscription dans des inventaires (COUTO, 1995). La vocation de l'histoire de l'art mexicaine fut de construire une identité nationale selon différentes approches. L'un de ses objectifs principaux fut de revaloriser les aspects artistique et civilisationnel des cultures préhispaniques en vue de construire l'idée 
d'une nation unie au passé glorieux. Il s'agissait également d'identifier l'originalité de l'art mexicain, et en quoi les expressions artistiques différaient de celles d'autres cultures. La recherche des particularités de la culture mexicaine entraîna la naissance d'un courant dans les arts et la philosophie connu sous le nom de Lo mexicano, auquel Octavio Paz et d'autres penseurs comme le philosophe Samuel Ramos ont contribué. La question de Lo mexicano s'est prolongée jusqu'au début des années 1980, époque à laquelle l'État, devenu relativement stable grâce à l'économie du pétrole, s'est brusquement effondré, fracturant la cohésion nationaliste (BARTRA, [1999] 2002a). Jusqu'alors, l'histoire de l'art dominante, à laquelle appartenaient par exemple Justino Fernández et Manuel Gamio, le fondateur de l'anthropologie et de l'archéologie moderne, épousait les principes idéologiques du libéralisme, en particulier la construction d'un passé ou d'un héritage fondé sur un monde préhispanique, qui consistait, de manière contradictoire, en une réconciliation des mondes colonial et moderne.

À la suite du mouvement étudiant de 1968, et du massacre à Tlatelolco de nombreux étudiants par l'armée ${ }^{2}$, apparut dans les années 1970 un courant critique résolu à démanteler les constructions imaginaires et celles du pouvoir réel afin d'établir d'autres chronologies. Il s'agissait de démonter, par de nouvelles recherches, ce que l'historien de l'art Fausto Ramírez a appelé " la fabrication de l'État " (Los pinceles..., 2003b). Dès lors, il n'est pas étonnant que soient apparues des histoires de l'art présentées comme nouvelles ou alternatives (ACEVEDO, 2001-2004). Celles-ci ont reconstruit les origines de la nation, démontrant comment les différentes formes de pouvoir ont participé à la constitution d'un État fort et quelles ont été leurs stratégies de représentation. La révision des origines de l'imaginaire nationale fut fondamentale, notamment pour la période connue sous le nom

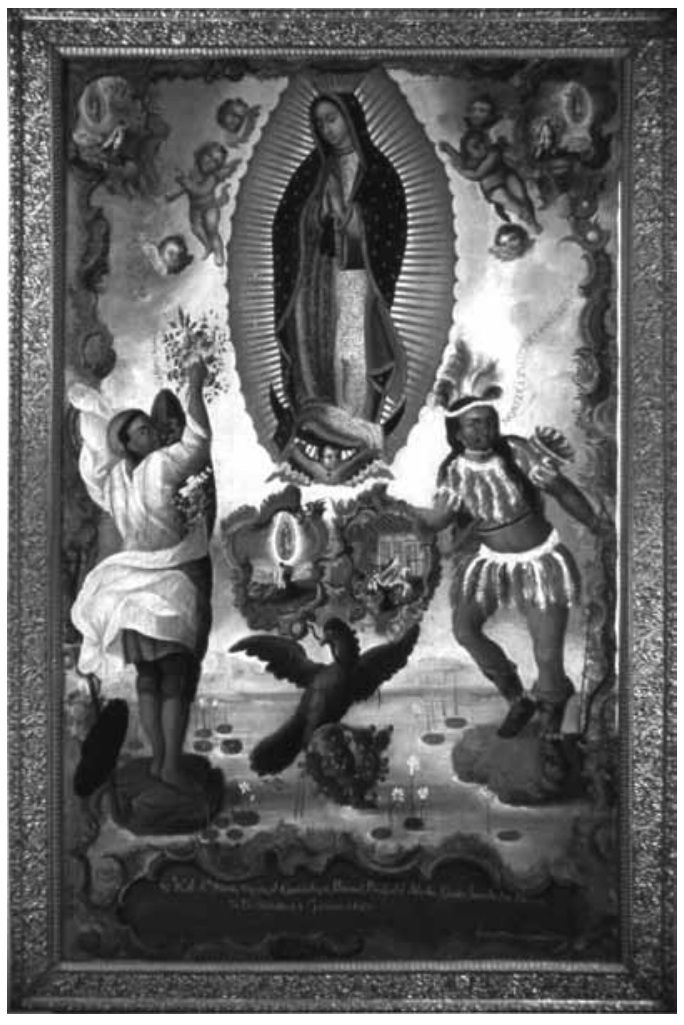
de Porfiriat (1877-1910), jusque-là identifiée par les artistes, les hommes politiques et les historiens comme la période d'incubation de la Révolution mexicaine. Ces questions ont conduit à réfléchir sur le sujet de l'utilisation du passé indien par le pouvoir, ainsi que sur les formes et les raisons de la réappropriation du passé préhispanique dans ses diverses origines. La vision monolithique de l'époque coloniale (1521-1810), vue tantôt comme le mal du Mexique, tantôt comme une période de prospérité et de splendeur dont l'art, les villages pittoresques, et les constructions civiques et religieuses (comme en témoigne le haut baroque qui s'est développé au XVIII ${ }^{\mathrm{e}}$ siècle) généraient de la nostalgie, a cédé le pas à une vision de la Nouvelle-Espagne qui contiendrait en elle le germe de modernités alternatives et d'identités culturelles propres - comme celle incarnée par le culte de la Vierge de Guadalupe (fig. 1 ; voir BRADING，2002a；CUADRIELLO， 2004 ; ECHEVERRÍA, 2007). 
Parallèlement, la lecture politique des œuvres d'art a été remise en cause durant ces trente dernières années. Les interprétations traditionnelles de l'art post-révolutionnaire (de 1920 à 1960), qui s'appuyaient sur une étude de l'iconographie politique, ont été à plusieurs reprises renversées. Les nouvelles approches, développées notamment par Ramirez et Renato González Mello, ont mis l'accent sur le fait que les ouvres les plus importantes de cette période, celles issues du muralisme mexicain, ne sont pas la traduction de symboles identitaires, patriotiques ou de l'ascension de nouvelles classes sociales ; un double langage y est décelable, l'un public pour satisfaire le régime, l'autre privé et qui, loin d'être transparent, présente une symbolique hermétique du pouvoir politique, équivalente à la franc-maçonnerie chez les libéraux (RAMÍREZ, 1983 ; GONZÁLEZ MELLO, 2008). Un des exemples les plus évidents, caractérisé par une grande complexité symbolique, est la fresque Omnisciencia, peinte

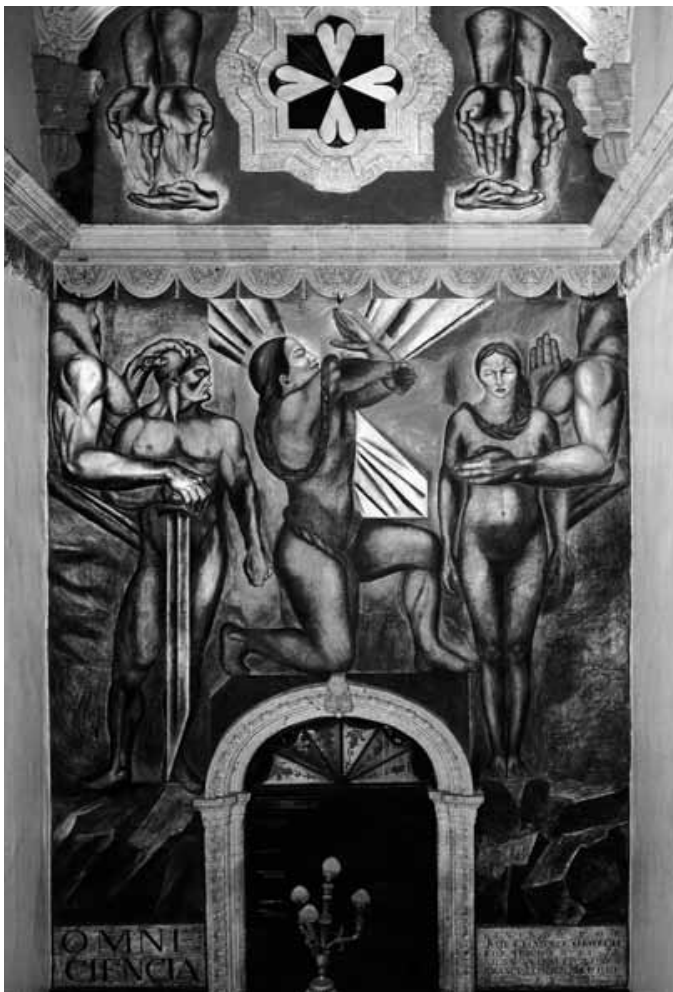

2. José Clemente Orozco, Omnisciencia, 1925, Mexico, Casa de los Azulejos. par José Clemente Orozco en 1925, dont le titre fait allusion à l'ésotérisme et qui évoque des principes, masculins et féminins, d'obéissance, de force, d'intelligence et de fécondité (1925, Mexico, Casa de los Azulejos ; fig. 2). L'étude de la presse et de la gravure de la Révolution au régime postrévolutionnaire a aussi permis de proposer des interprétations alternatives de la présentation du pouvoir en tant que corps politique moderne (Los pinceles..., 2003a). Des analyses du muralisme - récemment revalorisé, notamment par l'exposition sur Diego Rivera organisée au Museum of Modern Art (MoMA) à New York (Diego Rivera..., 2011) - ont invité à repenser les écarts entre l'appropriation de l'art par l'État et l'impact réel sur le public d'un langage visuel politique efficace.

\section{Architecture : identité(s) mexicaine(s) et modernisme d'État}

L'historiographie de l'architecture au Mexique s'est développée, en un certain sens, comme un champ parallèle et spécialisé par rapport à l'histoire de l'art. Si la peinture, durant la première moitié du XXe siècle, était considérée comme une tradition nationale au regard notamment de la pérennité du mouvement des muralistes mexicains, l'architecture, de la fin des années 1920 aux années 1930, présentait un champ d'expérimentation investi par les courants modernistes. Les créations du début de la carrière de Juan $\mathrm{O}^{\prime}$ Gorman déclinent le fonctionnalisme de manière particulière, tandis que les ouvrages de Luis Barragan, qui associent à la modernité un sens de l'espace préhispanique, sont les meilleurs exemples de l'architecture moderne mexicaine. Dans les années 1950, face à la croissance économique du pays, l'architecture offrait à l'État le moyen d'afficher une image forte de modernisation. Il privilégiait ainsi l'association du développement économique à l'image du progrès, au détriment d'une conception urbanistique qui valorise le passé. 
À la différence de l'histoire de l'architecture, qui s'est attardée sur le modernisme, l'histoire de l'art s'est concentrée sur les qualités symboliques de la place centrale de Mexico, lieu de l'unification des différents passés. Sur la place de la Constitution, connue aussi sous le nom de Zócalo, sont réunis, depuis le XVI ${ }^{\mathrm{e}}$ siècle lorsque fut construite la cathédrale, les bâtiments emblématiques des pouvoirs religieux et civique. L'historien de l'art Justino Fernández, considéré comme l'un des fondateurs de la discipline au Mexique, a décrit dans les années 1960 le centre historique de Mexico comme un lieu fondamental de l'identité nationale où sont conjugués tous les passés : "Nous sommes en relation actuelle et continue avec des œuvres des passés indien, espagnol, moderne (le XIX siècle) et immédiat, c'est-à-dire ce présent sur le point de devenir du passé [...] Il suffit d'une simple promenade sur la place de la Constitution et ses environs pour se retrouver face à d'importantes œuvres de toutes les époques historiques et constitutives de ce que nous sommes " ${ }^{3}$. Sur le côté nord du Zócalo se trouve en effet les ruines de ce grand temple, dit Templo Mayor, vestige de ce que fut l'immense ville de Tenochtitlan au temps des Aztèques (voir, entre autres, MATOS MoctezumA, 1994) ; sa découverte relativement récente, en 1978, et les fouilles qui ont suivi, ont montré une fois de plus que les Espagnols construisaient leurs églises sur les temples indiens. Cette juxtaposition culturelle caractérise le Mexique, produit d'un colonialisme où le mélange d'ethnies, les syncrétismes religieux et les nouvelles articulations sociales, visibles dans les coutumes et dans le langage, ont conduit à réfléchir à une modernité alternative ${ }^{4}$.

L'expansion urbaine accélérée, la croissance de la population et les nouvelles formes d'investissement de capitaux dans la construction ont interféré l'utopie de sites urbains empreints de valeur symbolique. Comme le fait remarquer Peter Krieger : « les usages, les modes de perception collective et les codes symboliques ont changé. En termes structurels, la place du centre historique doit entrer en concurrence avec les constructions suburbaines d'une mégalopole cloisonnée où s'amoncellent 20 millions d'habitants " ${ }^{5}$. Outre les facteurs cités à propos de l'avènement et de la croissance démesurée de villes au sein même des métropoles, qui détruisent les symboles d'autres époques, l'État a récemment tenté de donner une nouvelle orientation à l'ensemble des symboles nationaux, une attitude significative dans le cadre de notre sujet. Une des manifestations récentes de ce changement fut le projet de la construction en 2007 d'une immense tour pour célébrer le deux centième anniversaire de l'indépendance du Mexique, qui eut lieu en 1810 après presque trois cents ans de domination espagnole. L'emplacement prévu était justement à l'opposé du Zócalo, près de l'élégant centre financier à l'ouest de la ville où siègent plusieurs compagnies transnationales. Ironiquement, l'idée consciente ou inconsciente était de la construire près du monument dédié à la nationalisation du pétrole décidée en 1938 par Lázaro Cárdenas qui a soustrait aux mains étrangères cette ressource naturelle - une ressource qui éveillait bien entendu l'avidité des chefs d'entreprise nationaux et du capital international. L'immense tour, qui devait compter plus de soixante-dix étages et une hauteur de trois cents mètres (comme la Tour Eiffel), fut commandée à Rem Koolhaas. Cependant le gouvernement fédéral annula le projet, à la suite de la vague de protestations qu'il provoqua. Les images du projet montrent une sorte de pyramide tronquée censée rappeler les conceptions architecturales de l'ancien Mexique. La tour de Koolhaas avait pour but de combiner les intérêts des investissements privés de plusieurs groupes économiques - y compris celui de Carlos Slim, appelé l'homme le plus riche du monde - et une version modifiée de l'identité nationale. Ce projet est emblématique de la façon dont les nouvelles formes de capital, 
au-delà de la réussite économique, ont manifesté l'ambition de laisser une trace particulière dans l'espace urbain.

Le projet de Koolhaas s'inscrit dans une généalogie qui remonte à l'appropriation de l'architecture par l'État dans les années 1950, période $\mathrm{du}$ desarrollismo (1940-1968) pendant laquelle le pays s'est fortement modernisé. Les tours se sont en effet multipliées au cours des soixante dernières années, signes iconiques de la modernisation promue par l'État et de la volonté du gouvernement de laisser une trace dans la ville où siège le pouvoir. L'architecture de bâtiments publics et des nouvelles résidences construites pour les classes moyennes est ainsi devenue représentative de la modernité de l'État et de son développement effréné au cours de cette période. Les constructions encadrent et transforment l'image de la ville, comme la tour Latinoamericana de Augusto
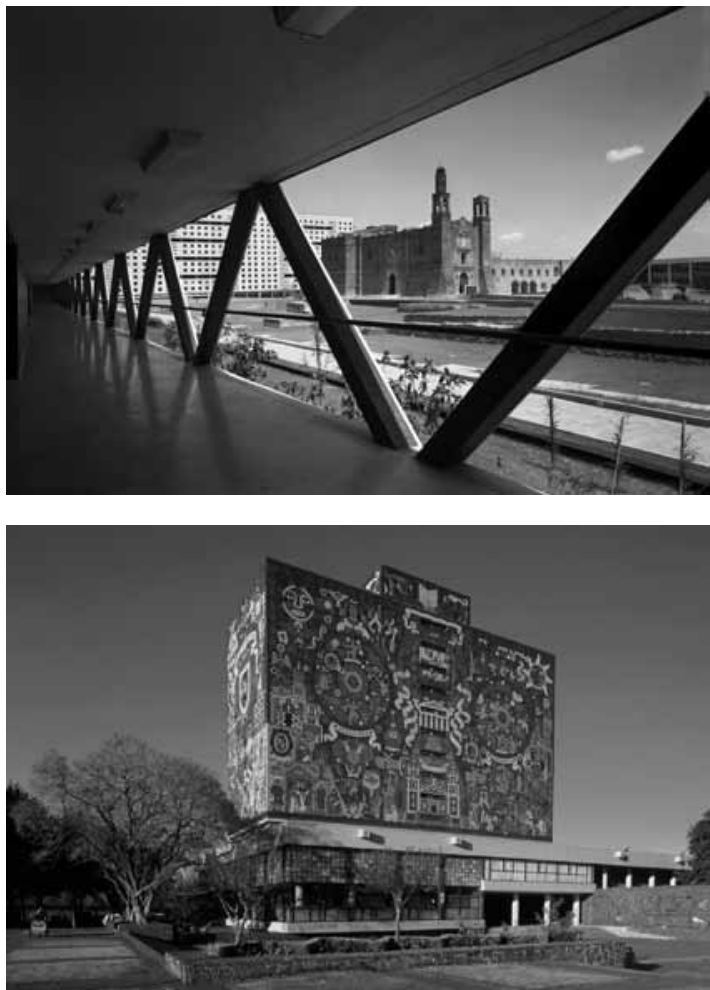

3. Plaza de las Tres Culturas, quartier NonoalcoTlatelolcao, Mexico.

4. Juan

O'Gorman, Bibliothèque centrale de la cité universitaire de la Universidad

Nacional

Autónoma de México, Mexico, 1950.

H. Alvarez construite en 1956 (HERNÁNDEZ Flores, 2012) ; elles deviennent aussi les points de repère des nouveaux centres de développement urbain, comme les tours de Ciudad Satélite de Mathias Goeritz édifiées en 1957. L'une des tours les plus visibles à Mexico est la tour Insignia conçue par Mario Pani Darqui en 1962 (JÁCOME, 2009) ${ }^{6}$, située au cœur d'un nouveau secteur urbain au nord de la ville et financée par l'État comme l'emblème du desarrollismo et de sa volonté de promouvoir les logements sociaux. La tour et les habitations se situent dans le quartier Nonoalco-Tlatelolco, qui une dizaine d'années plus tôt était un lieu si marginalisé que Luis Buñuel l'avait choisi pour tourner en 1952 son film Los Olvidados, qui retrace la vie d'adolescents rejetés vivant dans une misère sociale. Le projet architectural fut conçu autour d'une place où sont combinés des éléments architecturaux de l'ère préhispanique, une église coloniale et un complexe résidentiel moderne, renforçant ainsi la représentation de tous les passés réunis, en l'occurrence par l'État (fig. 3). D'autres exemples montrent cette alliance entre le modernisme et l'héritage des passés. Dans les immeubles fonctionnalistes comme ceux de l'université nationale - un modèle d'architecture moderne -, les murs sont recouverts de motifs peints ou en mosaïque inspirés d'iconographies murales anciennes. Un exemple significatif est la décoration de la Bibliothèque nationale réalisée par O'Gorman (fig. 4). Sans doute l'icône par excellence du Mexique et de la modernité, cet édifice à la structure fonctionnaliste est recouvert d'un foisonnement de motifs évocateurs du passé préhispanique (EDER, 2011). L'image de cette modernité fut cependant ternie par la suite. C'est près de la tour Insignia et dans le quartier Nonoalco-Tlatelolco, par exemple, que des centaines de jeunes furent assassinées en 1968, une période qui marqua le début du déclin de l'imaginaire national hérité du libéralisme. 


\section{Imaginaire et faits sociaux}

Comme l'ont considéré à juste titre les études postcoloniales, à l'instar des écrits de Homi K. Bhabha (BHABHA, 1990, 1995), la question nationale est une construction symbolique qui ne se forge pas uniquement au sein du territoire et du pouvoir national. Le nationalisme, qui va de pair avec la modernité, est tutélaire aujourd'hui du capitalisme mondial. Les symboles identitaires se divisent donc au Mexique, comme dans toutes les nations dépendantes de ce système, selon une double orientation intérieure et extérieure. Si l'État préserve jalousement ses signes nationaux comme stratégie de pouvoir, ils perdent leur capacité de représentativité, sans doute dans la mesure même où l'État s'affaiblit.

Par conséquent, comment aborder le sujet des arts visuels, de l'identité nationale et du pouvoir de l'État dans la conjoncture sociale et politique actuelle du Mexique ? L'imaginaire du pays est aujourd'hui le reflet de l'extrême violence des crimes liés au narcotrafic qui affecte la vie quotidienne des Mexicains, ces derniers devant concilier leur identité culturelle avec les images de violence diffusées dans les médias radiophoniques, télévisuels et numériques. Il me semble que la construction monolithique mexicaine qui lie les arts et l'État, garantie par une tradition historiographique tout aussi solide, s'est fracturée depuis longtemps. La rupture, qui s'est produite avec le mouvement étudiant de 1968, semble s'être consolidée vers le milieu des années 1970, avec la publication par l'historien Daniel Cossío Villegas d'une trilogie sur la structure du gouvernement mexicain qui fut extrêmement critique des procédures électorales et des abus de pouvoir dans le système présidentiel (Cosio Villegas, 1976). Dans le contexte de l'histoire et de l'anthropologie, de nouvelles analyses post-nationalistes et post-idéologiques, comme celles proposées par Roger Bartra dans ses deux ouvrages écrits dans les années 1980, Las redes imaginarias del poder político et La jaula de la melancolía (BARTRA, 1981, [1987] 2005), ont remis en cause le processus de désintégration de l'État. En outre, cette rupture n'était plus cantonnée à la sphère nationale mais avait dépassé les frontières; dans l'art contemporain, elle a conduit à une critique de la violence et à la dénonciation d'un État qui ne parvient plus à maîtriser l'ordre social, pas plus que sa représentation dans le domaine des arts.

Un exemple pertinent, relativement récent, est l'initiative du gouvernement du Mexique, d'institutions nationales et de fonds privés pour les arts d'envoyer l'installation de Teresa Margolles, De qué otra cosa podríamos hablar [De quoi d'autre pourrionsnous parler ?], à la 53e édition de la Biennale de Venise à l'été 2009. Le commissaire de l'exposition, Cuauhtémoc Médina, a aussi écrit l'introduction du catalogue, "Materialist Spectrality" (What else could..., 2009, p. 15-30). Celle-ci s'ouvre avec un rappel court mais efficace des nombreux morts au Mexique dus au narcotrafic, "un décompte alarmant " qui dépasse le nombre des victimes dans certaines régions du monde en guerre. À cette information générale, il faut ajouter, dit Medina, le rapport du département de Défense des États-Unis qui a mis en garde contre le possible effondrement du Mexique en raison de l'incapacité " d'un État faible et en faillite " de répondre de façon adéquate au crime organisé ${ }^{7}$. Pour le commissaire mexicain, l'installation de Margolles, étroitement lié au traitement institutionnel des cadavres et à la matérialité de la mort, représente un tournant dans son travail. Après avoir utilisé la morgue comme atelier puis avoir opté pour une esthétique minimaliste, ses dernières œuvres consistent aujourd'hui à se rendre sur les lieux où le narcotrafic a fait des victimes avec une équipe de collaborateurs qui se chargent de ramasser la boue, le sang et le verre cassé, après l'intervention du légiste 
et l'enlèvement des corps. Tous les résidus sont retravaillés par l'artiste pour les utiliser dans ses installations. Le sang et la crasse, mis à sécher sur une série de toiles humides, furent exposés lors de la Biennale dans un ancien palais vénitien. Les phrases prononcées par les témoins des crimes étaient imprimées sur les murs ou brodées au fil d'or sur des toiles imprégnées de sang (fig. 5). Le pavillon était lavé tous les jours, ce qui rendait plus évidente encore la présence de ce sang comme un processus sans fin. Bien que les organismes officiels aient tout d'abord autorisé l'accrochage, l'État désavoua l'exposition, retira son soutien et renvoya quelques fonctionnaires lorsqu'il comprit de quoi il s'agissait réellement.

Dans une autre perspective, la problématique du narcotrafic s'est également fait sentir en histoire de l'art académique, comme en témoigne l'article d'Ida Rodriguez Prampolini sur Jesús Malverde,

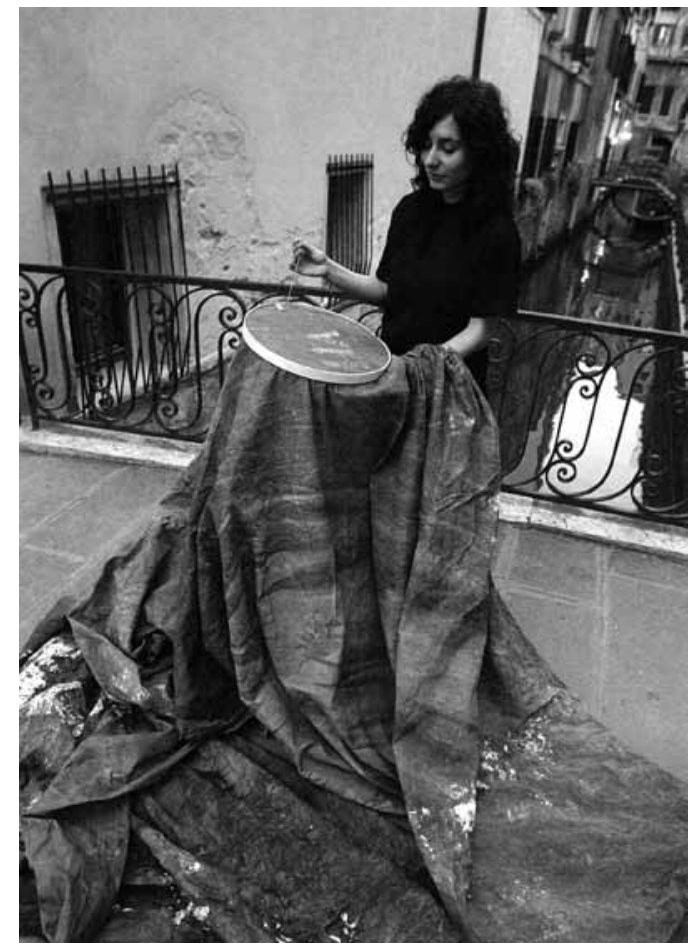
le saint patron des narcotrafiquants au Mexique (RODRÍGUEZ PRAMPOLINI, 2011). L'idée centrale de ce travail repose sur l'exploration, avec humour et perspicacité, de la fascination qu'exerce cette figure sur ses innombrables dévots. L'auteur examine des images religieuses provenant de la culture populaire mais aussi d'autres domaines, comme celles issues du cinéma et de ses idoles. Elle identifie les sources visuelles qui ont contribué à l'image de ce saint au visage jeune, habillé d'une élégante chemise de cow-boy nord-américain, et dont les bustes de toutes tailles sont largement diffusés dans le pays. Un autre objet de culte, visuellement à l'opposé mais complémentaire dans l'extravagance, accompagne celui de Malverde : la Santa Muerte, l'une des représentations religieuses les plus courantes ces derniers temps au Mexique. Malverde, au-delà d'un symbole religieux de culte, semble devenir un symbole national alternatif combinant l'économie, la peur et peut-être l'humour face à la mort, sujets que l'on retrouve notamment dans le culte du squelette.

Ce thème, si exploité qu'il en est devenu caractéristique des Mexicains, a particulièrement été développé au début du $\mathrm{XX}^{\mathrm{e}}$ siècle par le graveur José Guadalupe Posada. Le squelette comme motif a été un sujet constant dans l'analyse moderne de la sensibilité mexicaine, dont témoignent les références qu'en fait Sergei Eisenstein dans Que Viva México! en 1932, André Breton dans Souvenir du Mexique paru en 1939, ou encore Paul Westheim dans son essai La Calavera publié en 1957 (BRETON, 1939; WeSTHeIM, 1971). Récemment, de nombreux textes sociologiques et culturels ont été écrits sur la Santa Muerte, dont "El culto a la Santa Muerte: un estudio descriptivo », dirigé par Araujo Peña (PEÑA, 20052006). La différence entre la culture de la Calavera, qui relève de l'identité visuelle et psychologique mexicaine, et la Santa Muerte est directement liée à la nouvelle réalité du pouvoir parallèle narcotrafiquant par lequel la mort et l'illégalité sont devenues la norme. Bien que très peu de travaux portant sur la relation entre les arts et cette nouvelle violence 
soient parus, ce sujet intéresse nombre de jeunes historiens de l'art dont les thèses portent sur l'analyse de l'art contemporain mexicain, et plus particulièrement sur la photographie et les installations qui traitent de ces questions ${ }^{8}$.

\section{La fabrication de l'État}

Mais comment relier la situation actuelle des arts et de l'État à celle du passé forgée au fil des grandes expositions organisées sous l'égide de l'État et par l'écriture d'une histoire dont le but était de créer les imaginaires d'une nation unifiée et en paix ? S'emparant de la grandeur de son passé, l'État s'était donné l'image de ses magnifiques villes préhispaniques et des grands monolithes en pierre de ses anciens dieux, liés à la splendeur des autels coloniaux et au muralisme grandiloquent. À l'image de la phrase introductive de l'ouvrage encyclopédique Mexico a través de los siglos, publié entre 1884 et 1889, il rassemblait " tous les passés, ensemble, en harmonie " (RIVA PALACIO, 1884-1889). C'est une version du Mexique que l'on nomme ironiquement aujourd'hui " l'histoire de bronze ", en référence à une histoire soumise à l'idéologie nationale.

Les histoires nationales de l'art et leur historiographie proposent, me semble-t-il, une continuité qui permet de fixer une identité morale et esthétique de la nation. Pourtant, ce filage minutieux pour construire une tradition est actuellement remis en cause, vu désormais comme un ensemble de fragments contraints de se soumettre à une forme unique. La critique du pouvoir et de ses stratégies culturelles est une tradition intellectuelle mexicaine qui se poursuit parallèlement à l'homogénéisation des différences qui constituait une partie essentielle de l'idéologie d'un État fort. En témoignent les œuvres de Paz, y compris "Crítica de la Pirámide ", paru dans Postdata, et El ogro filantrópico (PAZ, 1970, [1979] 1981). Une de ses contributions importantes a été la revue Plural, publiée de 1971 à 1976, qui est devenue un espace de critique pour des écrivains attachés à l'analyse du système. Plural a été interrompu en 1975 par le gouvernement de Luis Echeverría Alvarez, l'une des figures politiques impliquées dans le massacre de Tlatelolco.

En 2003, le catalogue de l'exposition Los pinceles de la historia: la fabricación del Estado, 1864-1910 (Los pinceles..., 2003a), coordonné et écrit en grande partie par Fausto Ramírez, très connu pour ses recherches sur la fin du XIX siècle et le modernisme mexicain, et par Esther Acevedo, a joué un rôle important dans les recherches sur la constitution des histoires nationales. Il a jeté un regard novateur sur l'apparition de la peinture historique, étroitement liée à la consolidation de l'État moderne, postulant que l'apparition d'une peinture historique et laïque au XIX ${ }^{e}$ siècle a marqué des relations inédites entre les arts et un nouveau type de pouvoir. Les auteurs démontrent que c'est précisément à l'époque de l'intervention française au Mexique de 1864 à 1867, incarnée par Maximilien de Habsbourg, empereur du pays en 1864, qu'est née une peinture d'histoire mexicaine. Ce nouveau gouvernant était un grand amateur d'art, et il commença par assurer la permanence et la légitimité de son mandat en faisant créer une galerie de portraits de ses ancêtres dans la maison royale coloniale ; Maximilien vit en l'histoire le point de départ de son programme iconographique impérial, unissant son propre parcours au présent mexicain comme un prolongement de l'histoire européenne. Quelques semaines après son arrivée dans la capitale, Maximilien visita en juillet 1864 l'académie des Beaux-Arts de San Carlos, où il choisit des ouvres, puis il émit des décrets afin que soient édifiés des monuments à l'indépendance et aux différents héros. 
Si les libéraux avaient affirmé dans la reconnaissance d'un passé préhispanique la différence qui faisait d'eux des Mexicains, le nouvel empereur se chargea de promouvoir cette histoire en images et de la faire confluer au château de Chapultepec. À plusieurs reprises, Maximilien invita au palais des délégations de différentes cultures indigènes (ACEVEDO, 2003). On retiendra en particulier la rencontre entre l'empereur et un cortège d'Indiens kikapú, et la décision en 1865 de commander une peinture historique commémorant cette occasion à Jean-Adolphe Beaucé, arrivé au Mexique avec le corps expéditionnaire (1865, Artstetten, Erzerzog Franz Ferdinand-Museum ; fig. 6). Acevedo évoque les différents éléments intervenus dans la conception du tableau. Trois portraits à l'arrièreplan représentent des membres de la famille de Maximilien : l'empereur Napoléon III et sa femme Eugénie de Montijo et, entre eux, leur aïeul Habsbourg, Charles Quint. Acevedo attire l'attention sur le fait que Maximilien, dans des lettres adressées à son frère Napoléon III, parlait de ces Indiens comme des sauvages pittoresques, tandis que dans le tableau les deux groupes sont traités de façon proche, avec la même dignité. Plus qu'une image d'exotisme, le tableau semble évoquer le pouvoir occidental face à des races indigènes capables de se civiliser (ACEVEDO, 2003, p. 47-48).

Outre le Second Empire (1864-1967), Los pinceles de la historia (Los pinceles..., 2003a) fait état de deux périodes postérieures à l'exécution de Maximilien : la restauration de la République (1867-1876) et le Porfiriat (1877-1911). Ramírez explique qu'il s'agit d'époques de grandes compositions consacrées à l'histoire nationale, réalisées grâce aux fonds de l'État. Elles reflètent d'une part la force croissante du gouvernement, puissant et centralisé, et d'autre part la volonté d'un État-nation moderne prêt à mettre à contribution les arts visuels pour construire une image historique suggérant la fusion d'un passé prestigieux avec le présent, et aidant même à tracer les grandes lignes du destin national futur. Comprendre la façon dont les peintres d'histoire ont représenté les histoires nationales, c'est saisir le processus de construction de la nation évoqué par Tomás Pérez Vejo (PÉREZ VeJo, 2001). Ce dernier, en traitant l'invention de la nation et sa relation à un mythe moderne identitaire, repère également les contradictions entre la modernité et l'État centralisé.

Selon Ramírez, l'identification entre l'État, le gouvernement, la nation et la création d'un imaginaire qui la serve est fondamentale. Après les guerres sanglantes du milieu du XIX siècle, le pouvoir de l'Église a été restreint afin d'aboutir à la séparation entre l'Église et l'État, avec les Leyes de Reforma (1855-1860) initiée par Benito Juarez, qui devint président en 1858. Malgré la rédaction d'une Constitution en 1857, la démocratie n'a pas été viable. Ce n'est que durant la longue présidence de Porfirio Díaz, de 1880 à 1910, que le pouvoir absolu du président s'imposa. La conciliation des passés, souvent mentionnée, a servi non seulement à la constitution de la nation mais aussi à la centralisation du pouvoir.

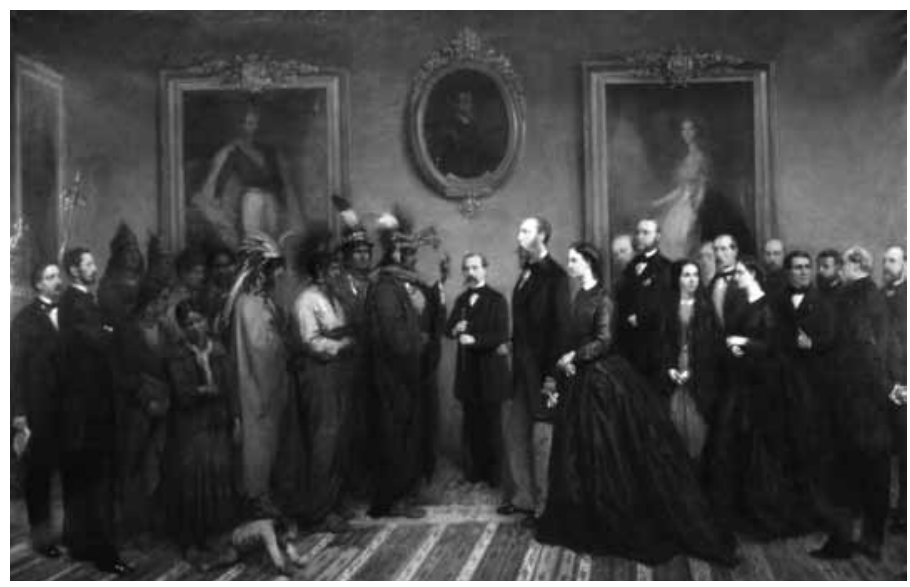

6. Jean-Adolphe Beaucé, Visite des Indiens kikapú à l'empereur Maximilien, 1865, Artstetten, Erzherzog Franz FerdinandMuseum. 
L'ouvrage México a través de los siglos (fig. 7), fut d'une grande importance dans cette entreprise, puisqu'il a servi de base pour créer les images d'une conciliation des passés - depuis l'époque préhispanique jusqu'à 1867 - tout en prenant bien soin d'éviter toute référence aux points de conflit, en particulier la période de la conquête du Mexique au XVI ${ }^{\mathrm{e}}$ siècle. Cette ouvre monumentale sur l'histoire mexicaine a également établi une tradition historiographique et a fourni indirectement la structure d'un scénario muséographique pour les arts qui a joué son rôle avec plus ou moins d'efficacité. Cette façon de présenter l'histoire a également longtemps influencé la représentation du Mexique, de l'Exposition universelle à Paris en 1889, sous l'égide de Porfirio Díaz, à la trilogie sur l'art du Mexique de Justino Fernández (FERNÁNDEZ [Justino], 1962), notamment dans sa conception du pays comme projet civilisationnel constitué de tous ses passés, et comme ressource du mythe moderne d'identité. Cette vision fut même décelable dans l'exposition décevante México eterno: arte y permanencia de 1999 (México eterno..., 1999), dont le titre présageait un événement tout autrement surprenant : la chute du parti révolutionnaire institutionnel qui a gouverné le pays pendant soixante-dix ans.

\section{La culture indienne, des Expositions universelles à la peinture d'histoire}

Dans son livre consacré à la participation du Mexique aux expositions universelles entre 1880 et 1930, Maurice Tenorio analyse la présence du pays dans ce type de rencontre mondiale, révélant des concordances entre la formation d'une nation moderne et ses affinités avec des problèmes plus vastes et généraux comme le nationalisme, le cosmopolitisme et le modernisme occidental (TENORIO, 1998, p. 9). En d'autres termes, son argumentation consiste à établir les particularités de la nation moderne mexicaine en construction dans un contexte qui n'est plus seulement local.

Pour le sujet qui nous occupe, l'Exposition universelle la plus significative $\mathrm{du}$ XIX ${ }^{e}$ siècle est celle de 1889 à Paris. Tenorio a étudié en profondeur le pavillon mexicain, le Palais aztèque (fig. 8), en faisant appel à toutes les sources possibles (lettres, archives, etc.), et en échafaudant une argumentation méticuleuse et systémique. Il analyse sa matérialité, sa structure, son décor et les stratégies visuelles mises en place par un appareil propagandiste impressionnant. Son étude permet de conclure à une volonté de représentation nationale et cosmopolite. Il convient également de souligner les aspects considérés comme les plus remarquables du pavillon mexicain, soit l'art, l'éducation et les textiles.

7. Vicente Riva

Palacio éd.,

México a través

de los siglos,

Mexico, 1884-

1889 , couverture

de l'édition

de 1953.

8. Le Palais

aztèque, pavillon

mexicain à

l'Exposition

universelle de

Paris en 1889.
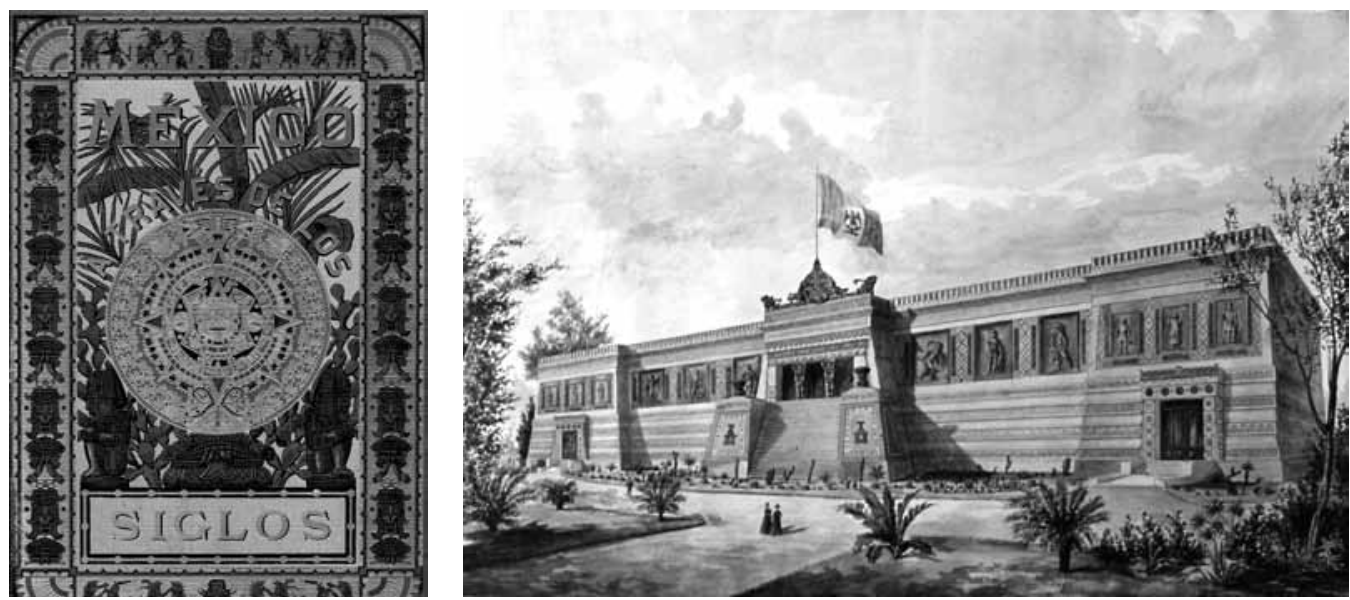
Dans cette longue recherche, Tenorio insère le Palais aztèque dans le débat architectural au Mexique et en France : quel est le style le plus adéquat pour représenter la nation à une époque de discrédit du néoclassicisme et d'admiration pour une technologie moderne exacerbée, symbolisée par la Tour Eiffel ? Le pavillon mexicain, conçu sur le modèle du téocalli ou temple préhispanique, s'inscrit dans le renouveau stylistique du XIX ${ }^{e}$ siècle qui consiste à faire revivre le passé, et à réunir et combiner des styles d'époques différentes. Il était décoré de divinités et de héros préhispaniques avec, à l'intérieur, un mélange de peintures académiques et de paysage ; les matières premières utilisées, de nature industrielle, étaient affichées pour attirer les investissements étrangers. Paris, lieu d'exposition où trônait dans toute sa splendeur l'exploit ferronnier de Gustave Eiffel, rendait difficile une mise en parallèle avec le Mexique, malgré l'optimisme du président mexicain Díaz. S'il était désireux de faire montre de progrès, l'édifice mexicain relevait aussi de l'exotisme, très courant dans les Expositions universelles.

Tenorio propose une comparaison ingénieuse entre le Palais aztèque et la publication México a través de los siglos, achevés la même année, qui représentent symboliquement, pour lui, les origines idéologiques d'une nation moderne. Les travaux de Fausto Ramírez complètent cette interprétation (RAMÍREZ, 2003). Un des modèles de pensée propagé par la série provient d'Alfredo Chavero, historien, archéologue et auteur du cinquième volume de Mexico a través de los siglos : il y souligne l'importance de la culture náhuatl - celle des Aztèques au-dessus de toutes les autres, en la proclamant, dans une perspective évolutionniste, comme étant la plus forte. Peut-être trouve-t-on ici l'origine de l'appropriation de la période aztèque par les libéraux à la fin du XIX ${ }^{e}$ siècle, en tant que passé le plus significatif pour la nation moderne (EDER, 2012) ${ }^{9}$. Pour Tenorio, le Palais aztèque, que les propagandistes de l'exposition présentaient comme " un bâtiment dont les lignes et la composition caractérisent l'architecture des races les plus civilisées du Mexique $"{ }^{10}$, représente l'aboutissement d'un long conflit sur la question indigène posée dans l'écriture de l'histoire. Tenorio, tout comme d'autres chercheurs, souligne la façon dont la dimension indienne a été mise en valeur d'un point de vue social, politique et artistique en vue de constituer une identité propre qui se différencie de celle de l'Espagne, mais aussi de celle des États-Unis.

Dans un article largement diffusé, Ida Rodríguez Prampolini donne un autre aperçu du sujet (RoDríGUEZ PRAMPOLINI, 1988). D'après elle, l'image de l'Indien dans la peinture du XIX ${ }^{e}$ siècle n'est pas envisagée selon le contraste entre sa condition réelle de dépossédé et sa représentation ; au contraire, l'analyse de ces œuvres donne à voir sa condition de soumission : " La silhouette sombre de l'Indien entre dans la peinture savante, celle de l'Académie, par un coin du tableau, alors qu'il est dans une attitude de soumission, à genoux. Il apparaît, en 1850, lorsque le peintre Juan Cordero le peint dans son tableau Christophe Colomb devant les rois catholiques, puisque le tableau a pour sujet la présentation à Ferdinand et Isabelle des natifs du Nouveau Monde, en attitude révérencieuse. Deux hommes forts à la peau brune et une belle femme, mais d'une beauté en quelque sorte éloignée des canons de l'idéalisme classiciste puisque ses traits sont ceux d'une métisse, s'inclinent devant les rois et leur offrent les trésors de leur terre perdue, présentés dans un coffre et sur un plateau ${ }^{11}$. L'exemple du tableau de Juan Cordero (1850, Mexico, Collection Palacio national de Bellas Artes ; fig. 9) permet à Rodríguez Prampolini de développer longuement le sous-texte des diverses apologies du monde indigène au XIX ${ }^{e}$ siècle, face à un débat politique dans lequel l'Indien était encore désigné comme un sauvage. Sa thèse générale, sauf exception, est que la présentation de l'identité indienne comme symbole national dans les peintures du XIX ${ }^{\mathrm{e}}$ siècle et même du XX $\mathrm{X}^{\mathrm{e}}$ siècle n'est qu'une posture utilitaire. Les nombreux programmes politiques revendiquant la défense 


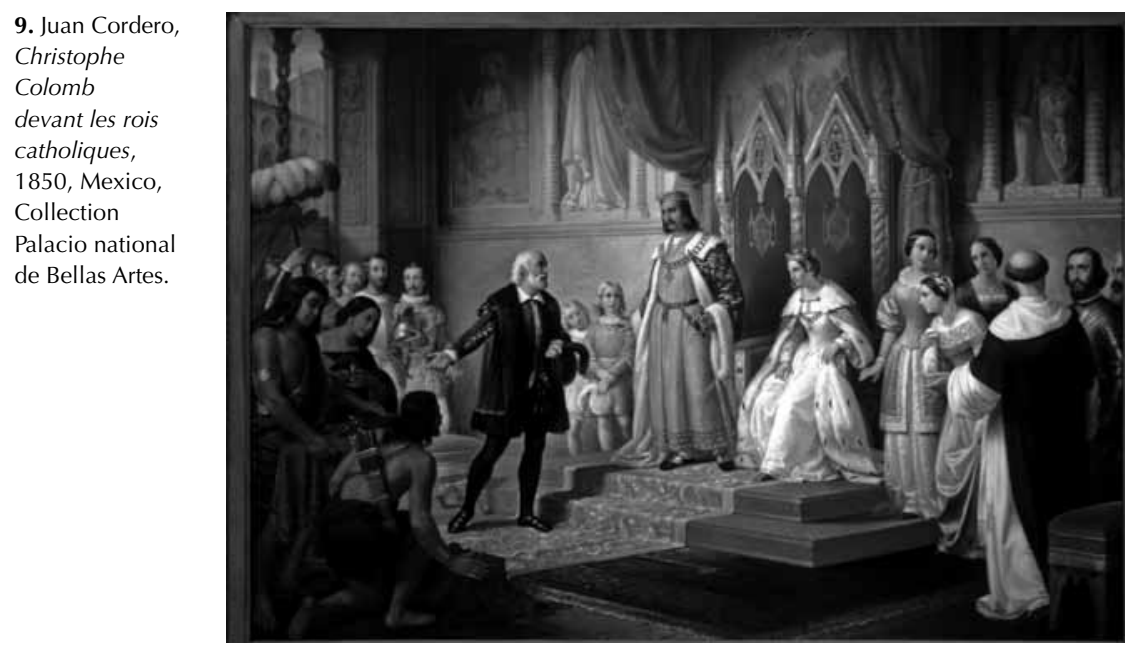

de cette identité et le respect de sa différence sont en effet encore loin d'être menés à bien. L'analyse soigneuse de l'iconographie de l'Indien traitant les distorsions, les idéalisations et les accoutrements, ainsi que les positions et les manières de faire entrer en scène cette figure dans les tableaux, rend effectivement compte de l'invention d'un langage visuel qui révèle une coexistence difficile avec cet "autre "

que les programmes politiques ont pourtant acclamé et revendiqué comme partie intégrante d'un "nous ». L'histoire donna toutefois raison à Rodríguez Prampolini, puisque, en 1994, au moment des changements initiés par le président de la République Carlos Salinas, les Indiens du Chiapas, avec le mouvement zapatiste et le sous-commandant Marcos, ont inauguré une nouvelle façon de faire de la politique qui a déconcerté le gouvernement en mettant à mal les imaginaires liés à l'identité indienne comme appartenant à la nation. Plus récemment, les réelles conditions de vie et les nouveaux modes de représentation de l'Indien et de ses structures sociales ont commencé à se diffuser par le biais des réseaux sociaux sur Internet.

\section{Le muralisme : la Révolution, l'être national et l'indigénisme}

Dans son brillant essai Octavio Paz y la poética de la historia mexicana, David Brading donne une analyse de la conception de la nation mexicaine telle qu'elle est développée dans l'œuvre du poète (BRADING, 2002b ; voir aussi PAZ [1950] 1981). Brading ouvre son étude par un portrait synthétique de José Vasconcelos, intellectuel et homme politique nommé ministre de l'Éducation en 1921 qui a joué un rôle important dans la conception des politiques culturelles découlant de la Révolution de 1910. De formation philosophique éclectique, Vasconcelos proposait une croisade éducative qui définirait " les caractères d'une culture mexicaine $~^{12}$ bien différenciée de la culture européenne, et il a réussi à promouvoir un mouvement culturel fort autour de différents arts, en particulier la peinture murale. On trouve dans son discours de grands accents nationalistes et une certaine conception de la race : il fait allusion par là aux peuples indiens et aux Mexicains en général, en les exhortant à sortir de leur léthargie et à contribuer à la formation d'une nouvelle culture, bien différenciée de la culture européenne - c'est-à-dire la culture française. Selon Brading, les muralistes les plus connus comme Orozco, Rivera et David Alfaro Siqueiros ont rendu compte dans leurs peintures des différentes conceptions et des débats sur la notion d'identité nationale, dont la dimension constitutive indienne et la dimension nationale moderne figuraient parmi les thèmes principaux (BRADING, 2002b).

Si les représentations construisent les imaginaires, les peintures murales ont sans doute été les plus puissantes de l'histoire moderne du Mexique et elles entretinrent avec le pouvoir des relations complexes. Selon Brading, ce sont ces œuvres qui ont donné leur identité au nouvel État né d'une Révolution qui avait engendré une lutte factionnelle sanglante et avait 
entraîné le chaos et une perte de repères (BRADING, 2004, p. 19). Cependant le muralisme a touché d'autres cordes sensibles, en particulier le problème indien et les imaginaires de son passé dans la population indienne et métisse elle-même. Les fresques didactiques de Rivera, qui s'adressent à des groupes d'origines sociales et culturelles diverses, en sont un bon exemple. Lorsqu'on leur pose la question des raisons de leur visite, la réponse surprenante de la plupart des spectateurs est la suivante : "Nous sommes venus rendre visite à nos ancêtres ", ce qui pourrait sembler anecdotique si ce n'était corroboré par des études sur le public du muralisme développées par Graciela Schmilchuk (SCHMILCHUK, 1994). Combinant l'observation de terrain, des indicateurs multiples et des entretiens qui confrontent différents types de publics à des questions sur le réel et l'imaginaire, le travail de Schmilchuk incite à réfléchir sur les différentes appropriations des symboles de l'histoire par l'État et la problématique des subjectivités face aux représentations de la peinture d'histoire. Il semblerait que le muralisme ne soit pas toujours perçu comme la représentation idéologique de l'État, indiquant le succès de la formule de cet art public. Pour une raison indéterminée, certains spectateurs, avec des niveaux d'éducation différents, voient dans les fresques, en particulier celles de Diego Rivera, des images bien vivantes, témoignages du pouvoir de représentation du passé indien qui légitime sa place dans l'histoire. Cette peinture historique, dotée de caractéristiques différentes de celles du style académique du XIXe siècle, a en quelque sorte réussi par la stratégie du support, la fresque en l'occurrence, à dépasser peut-être la représentation symbolique de l'État en créant une relation directe avec le public.

Il n'est d'ailleurs pas anodin que le MoMA à New York - qui a réalisé d'importantes expositions sur l'art mexicain bien qu'il n'ait manifesté que peu d'intérêt à son égard pendant longtemps - se soit décidé, quatre-vingts ans après avoir présenté la dernière grande rétrospective sur Rivera, à exposer des fresques portatives du peintre. Cette fois, face à ses œuvres, ce ne sont pas les Indiens qui se sont reconnus en elles mais le mouvement dit des Indignés. Le directeur du MoMA, Glenn Lowry, lors de l'inauguration, a dit dans sa déclaration de presse : "Dans le contexte actuel du mouvement 'Occupy Wall Street', je ne peux m'empêcher de penser à la société stratifiée qui apparaît dans l'œuvre de Rivera ${ }^{13}$ (NotimeX, 2011 ; LemUs, 2011 ). Lowry faisait allusion à la fresque portative Activos congelados peinte entre 1931 et 1932, qui offre l'image d'une ville de New York stratifiée, discordante et divisée par les inégalités économiques (Mexico, Museo Dolores Olmedo ; fig. 10). La fresque, peinte dans des tons rosés et gris, dont la perspective maîtrisée et le dessin architectural attirent l'œil, est composée de trois parties : la partie supérieure donne à voir le paysage urbain de New York, avec les gratte-ciel comme emblème de beauté et de pouvoir économique ; celle du bas renvoie à une chambre forte souterraine voûtée et grillagée, dont les portes sont fermées aux clients ; au centre,

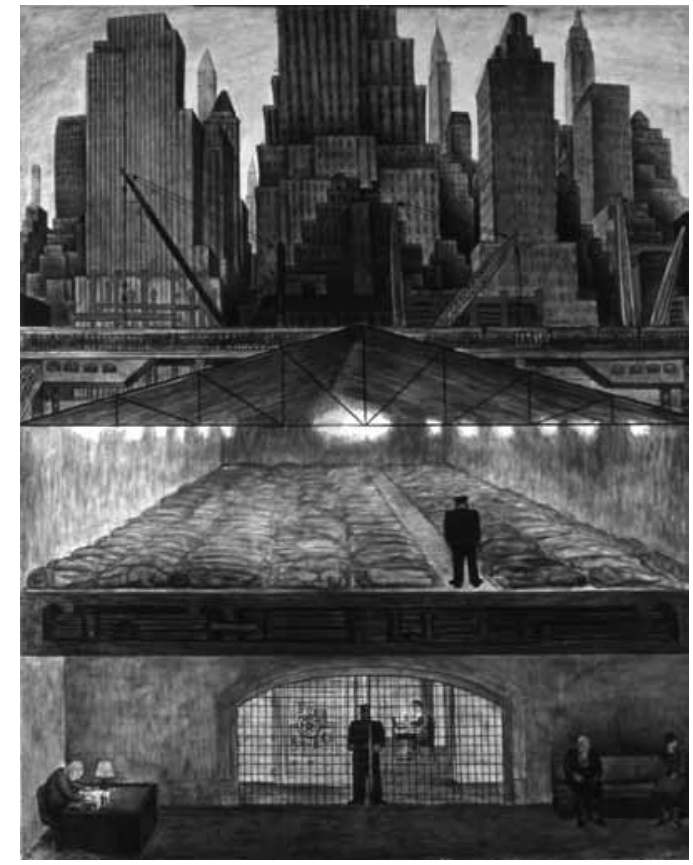

10. Diego Rivera, Activos congelados, 1931 Mexico, Museo Dolores Olmedo. 
on peut voir une sorte de hangar surveillé par un unique policier, où gisent au sol des cadavres. Peint en pleine crise du capitalisme dans les années 1930, ce tableau devient pour les Indignés le symbole des manigances du capitalisme, de son manque de transparence total comme de ses effets néfastes sur l'économie et la vie quotidienne - dettes et surtout chômage. Les musées étant bien évidemment aussi des lieux de pouvoir qui exaltent les artistes et les périodes historiques, il semble étonnant que le MoMA, qui compte au sein de ses instances dirigeantes quelques personnes du monde de la finance, prenne l'initiative de trouver des parallélismes entre certaines œuvres de Rivera et le mouvement des Indignés.

Les relations qu'ont entretenues Rivera, Orozco et Siqueiros avec la politique, l'État et le mécénat américain ont fait l'objet d'analyses rigoureuses et de nouveaux éclairages (CARdozA y ARAgón et al., 1983 ; RAMÌREZ, 1983 ; DEBRoISE et al., 1996 ; MILIOTES, GONZÁLEZ MELLO, 2002 ; AZUELA, 2005 ; EDER, 2007 ; GONZÁLEZ MELLO, 2008). J'ai cependant voulu ici suggérer les variantes que leur réception introduit dans les relations entre l'art et le pouvoir, et accentuer le fait que ce travail et la forte présence des principaux muralistes aux États-Unis ont donné un point de vue nouveau à leurs conceptions historiques et à leur capacité d'expérimentation. Si c'est là un aspect de l'histoire, l'autre est la manière dont l'État s'est emparé de ces œuvres au moyen de ce que Renato González Mello a appelé le " canon libéral ». Dans sa conception étatique de l'histoire, cette peinture adopte en effet des iconographies qui apparaissaient déjà - certes avec des différences de style et d'expression - dans la première peinture d'histoire du XIX siècle.

Ainsi, la représentation de l'État dans les arts s'est manifestée surtout dans la peinture dès le XIX ${ }^{e}$ siècle et ce jusqu'à la peinture murale. Quand le pouvoir s'est approprié l'architecture, il a recherché un mélange de " mexicanité " et de modernisme comme dans le cas du Palais aztèque et dans les décors de nombreux bâtiments publics, comme ceux de la Bibliothèque nationale. Ce fut une négociation complexe entre l'État et les artistes, ces derniers étant pleinement convaincus qu'il s'agissait du véritable chemin d'un art mexicain, tandis que le pouvoir, sans l'exiger directement, y trouvait le symbole de la nation.

\section{Plus de modernité, moins d'histoire}

Cette dynamique établie entre l'art, l'État, les politiques culturelles et l'histoire de l'art, qui ont participé - de manière consciente ou inconsciente - à la construction d'une vision unifiée et singulière de l'identité nationale mexicaine, a commencé à s'essouffler vers la fin des années 1980. L'influence croissante de tendances néolibérales à partir du début des années 1990 a modifié sensiblement la politique culturelle de l'État, qui cherchait à se distancier de l'approche monolithique de ses prédécesseurs en cultivant une vision plus nuancée, composite, de la modernité.

Ainsi, le président Carlos Salinas de Gortari a commissionné par le biais du ministère de la Culture une exposition intitulée Modernidad y modernización en el arte mexicano, qui eut lieu en 1991 au Musée national d'art (Modernidad..., 1991). La manifestation, qui eut pour commissaire et coordonnateur l'écrivain et critique Olivier Debroise, avait pour but de présenter un regard nouveau sur l'époque des années 1920 à 1960, dominée par le muralisme mexicain. Cette manifestation s'est avérée une réflexion riche sur les divergences, les tensions et les rencontres entre l'avant-garde et le nationalisme, et qui reconsidérait l'utilisation et le poids du concept de modernité dans les arts mais aussi au sein de la société. Néstor García Canclini, dans son célèbre livre Culturas híbridas, estrategias para salir y entrar de la modernidad (GARCÍA CANCLINI, 1988), avait déjà entamé une réflexion sur la fracture de la modernité qui 
forçait à repenser la construction des sociétés latino-américaines en tant qu'entités hybrides. Composites en termes ethniques et religieux, ces sociétés, selon lui, étaient constituées d'un certain nombre de couches culturelles et de systèmes économiques convergents et divergents, produisant une modernité atypique - ce que nous avons déjà révélé avec l'exemple de l'architecture. Debroise, en partie influencé par ce corpus théorique qui remettait en cause l'efficacité de la modernité et les possibles modèles alternatifs, a réalisé une exposition et un catalogue exemplaires. Son introduction est un guide pour réécrire l'histoire de l'art au Mexique, non pas selon une continuité, une évolution ou une harmonie, mais selon une tension entre des éléments opposés, dans un débat entre le national, le nationalisme et son fidèle compagnon, le réalisme - tout en laissant une place aux artistes qui cherchaient à renouveler le langage des arts visuels (DEBROISE et al., 1996, p. 27-42).

La controverse suscitée par cette manifestation fut bénéfique et réellement importante dans le domaine de la critique et de l'histoire de l'art, mais elle est aussi révélatrice de la relation entre l'art et le pouvoir. Parallèlement à la modernité artistique, être moderne en politique signifiait en effet privatiser et contrôler l'ingérence de l'État avec les conséquences que l'on sait, surtout pour les pays pauvres. Dans la mesure où la subvention de tels événements destinés à faire circuler le concept de modernité avait pour but ultérieur, dans le contexte géopolitique du traité de libre-échange avec les États-Unis et le Canada, de participer à une opération de transformation du protectionnisme économique de l'État et de promouvoir le libéralisme économique, le nationalisme d'État et sa représentation dans les arts traditionnels au Mexique commençaient à être gênants.

Face à ce malaise, nourri par des propositions comme celles de García Canclini, le discours artistique a commencé dans les dernières décennies du $\mathrm{XX}^{\mathrm{e}}$ siècle à se démultiplier et se décentrer pour embrasser des sujets et des questions auparavant laissés dans l'ombre. Cette évolution fut en partie facilitée par la tradition très riche de l'art public, incarné par le muralisme mais aussi par de nombreuses autres initiatives. En effet, la relation très vivante entretenue avec les villes et leurs monuments offre une vision à la fois moins homogène et plus populaire de la relation entre l'art et le pouvoir. Les fresques innombrables qui ont surgi dans tout le pays, et l'apparition constante sur les places, les avenues et parfois au milieu de nulle part de statues des héros - du mouvement de l'indépendance ou de la Révolution mexicaine - faites par des anonymes ou par des sculpteurs célèbres s'apparentent à autant de représentations officielles ou de modes de résistance (dans le cas de la production dans certaines petites villes qui rompt avec le canon officiel).

Comme l'ont démontré Paulo Gori et Helen Escobedo dans leur livre Mexican Monuments: Strange Encounters paru en 1988 (GORI, ESCOBEDO, 1988), une augmentation de la diversité sculpturale se produit, qui envahit le pays à travers des monuments populaires et officiels. Jusqu'au début des années 1980, ces œuvres privilégiaient le réalisme dans de magistraux hommages aux héros de la patrie, qui étaient représentés par des statues en pied avec d'immenses têtes, dont la ressemblance à divers présidents était parfois frappante. En ce sens, l'art public est tantôt en accord tantôt en désaccord avec les intentions officielles. La tour Estela de la Luz, commémorant les deux cents ans d'indépendance et le centenaire de la révolution mexicaine, de plus de cent mètres de haut, qui a remplacé le projet de Koolhaas mentionné plus haut, présente des formes discursives vides de sens qui ont provoqué une réaction populaire face à ce symbole national qui lui a été imposé. Ce monument a été reconstitué dans les réseaux sociaux sous la forme d'une crypte qui porte l'inscription " 50000 », qui est le nombre de morts dus au narcotrafic au cours des dernières années ${ }^{14}$. 


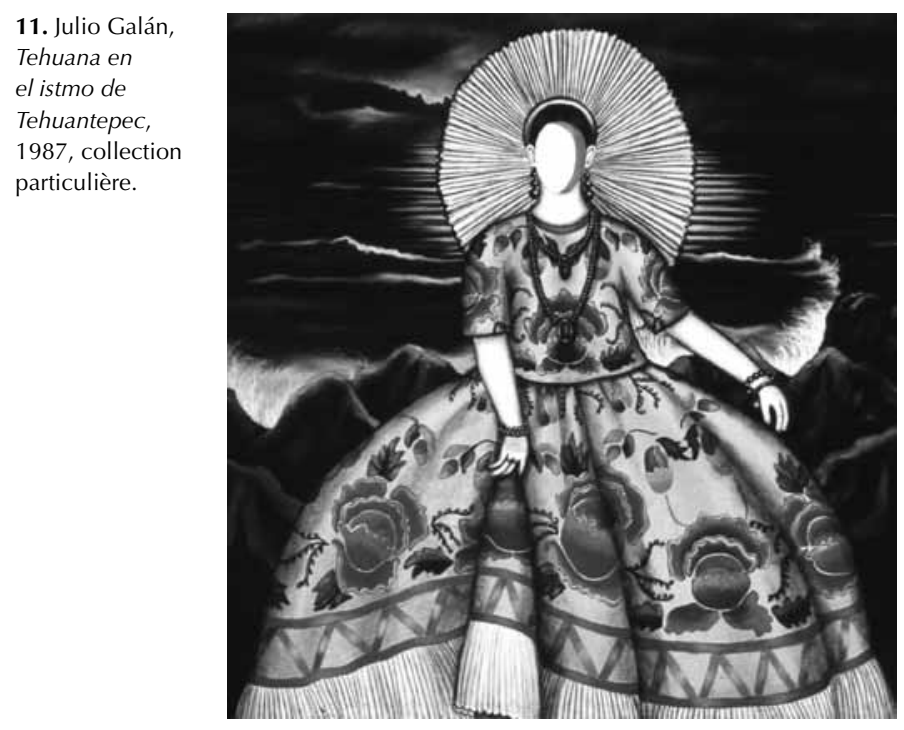

Aujourd'hui ce sujet fondamental qu'est la relation entre l'art et le pouvoir s'épuise; le thème de la violence s'est emparé des symboles nationaux et a supplanté toutes les priorités. Il appartient à l'art contemporain mexicain d'articuler l'autre aspect du pouvoir de l'État. Au cours des années 1980, un groupe d'artistes s'est approprié les symboles nationaux en fondant le neomexicanismo, mouvement pictural qui s'intéressait au lien entre le patriotique sacré et l'art populaire ou le kitsch. Ils ont attaqué des aspects différents de l'identité nationale associés au machisme, à une culture patriarcale affectant la subjectivité, et à la question du genre, ou comment être homosexuel dans un contexte où les valeurs établies sont celles du patriotisme et de la religion. Le neomexicanismo, ainsi que d'autres courants qui ont critiqué l'État et son contrôle autoritaire de l'identité nationale, ont touché à un sujet fondamental : comment être une minorité et s'identifier à l'État (SÁNCHEZ, 2001) ? L'une des œuvres iconiques du neomexicanismo est Tehuana en el istmo de Tehuantepec de Julio Galán (1987, collection particulière ; fig. 11). Dans ce tableau dont l'esthétique rappelle celle d'une affiche, le paysage foncé de l'isthme sert de toile de fond à une femme vêtue d'un costume régional ; sa robe richement brodée occupe tout l'espace du tableau, mais le peintre a choisi de ne pas lui donner de visage. La dénationalisation des symboles de l'identité mexicaine trouve dans ce tableau un exemple important : l'aspect décoratif prévaut ici sur un signifié vide, tout en suggérant une ambiguïté sexuelle.

Durant cette première décennie du XXI ${ }^{\mathrm{e}}$ siècle, l'une des tâches principales des spécialistes a été de reconstruire le discours sur l'art contemporain en déterminant ses chronologies et le processus de son détachement de la question de l'identité nationale et des politiques d'État. Cela a abouti à l'exposition La era de la discrepancia (La era..., 2007) au musée universitaire des Sciences et des Arts de l'UNAM (MUCA) dirigée par Olivier Debroise et Cuauhtémoc Medina, qui couvrait toute la période du mouvement de 1968 à la fin du XXe siècle. L'objectif de cette exposition était de montrer les changements de langage dans les arts visuels, qui ont dû d'abord se confronter à la tradition durable des réalismes qui ont prédominé jusqu'aux années 1950, puis à celle du muralisme, dont les principaux protagonistes jouissaient d'une certaine forme de pouvoir dans le cadre artistique.

La construction de l'État mexicain tel qu'il voulait être présenté par le pouvoir constitue un appareil de dimension nationale - aspirant à centraliser et à contrôler les désirs, les imaginaires, les subjectivités et une certaine idée de l'histoire. Pour ce faire, il a engagé artistes, critiques, historiens de l'art, collectionneurs et certains acteurs des secteurs privés convaincus du lien inextricable entre l'État et les arts dans la définition de l'identité nationale. Désormais, cette problématique est impossible à comprendre sans considérer les tensions et les désaccords entre le public et les intellectuels, et le démantèlement de l'histoire officielle et de ses stratégies de représentation dans les arts visuels. 


\section{Notes}

Ce texte a été traduit par Vanessa Capieu.

1. Dans "Nationalisme créole et libéralisme mexicain ", troisième chapitre de son livre Los Orígenes del nacionalism mexicano, David Brading se pose une question fondamentale : pour quelles raisons le libéralisme classique a-t-il reçu tant d'appui au Mexique? Sa tentative de réponse, bien documentée, soutient qu'il s'agit d'un mouvement différent de celui de l'Europe, des États-Unis et d'autres pays d'Amérique latine, dans la mesure où il avait pour mission non seulement de protéger les intérêts d'une nouvelle classe mais aussi d'inclure les couches les plus pauvres de la société mexicaine, dont les Indiens et le bas peuple qui avaient pris part aux luttes intestines propres aux mouvements post-indépendantistes. Dans le même temps, c'est une forme de libéralisme qui a posé la question de la nécessité d'un État moderne, et dont le modèle se rapproche de celui de la France ou des États-Unis, raison pour laquelle il a été indispensable de se battre pour un État laïque et démilitarisé (BRADING, [1980] 1988 , p. 125-126).

2. Dans "Crítica de la Pirámide ", un texte écrit à la suite du massacre de Tlatelolco en 1968, Paz fait une exégèse du pouvoir au Mexique et se questionne sur les relations entre les pouvoirs absolus d'un État censé être moderne et les rapports existant avec un passé préhispanique qui réclamait sacrifice et bains de sang. Il compare ainsi l'autoritarisme de l'État mexicain à celui des Aztèques, la culture choisie par les libéraux comme la plus représentative parmi toutes les cultures préhispaniques, et trouve en elle les fantômes qui hantent l'identité nationale du Mexique du XX ${ }^{\mathrm{e}}$ siècle (PAZ, 1970).

3. "... Estamos en relación actual y continua con obras del pasado indígena, del pasado español, del pasado moderno (el siglo XIX) y del inmediato pasado, o sea del presente que va pasando a pasado [...] Un corto paseo por la Plaza de la Constitución y sus inmediaciones es suficiente para encontrar obras importantes de todos nuestros tiempos históricos " (FERNÁNDEZ [Justino], 1972, p. 8).

4. Néstor García Canclini et Bolívar Echeverría proposent des modèles de modernité alternative sensiblement différents, à partir justement d'une société basée sur la différence et sur la juxtaposition des époques et des cultures. Les fusions ethniques et le métissage, dont les peintures dites de castes sont un bel exemple, sont devenues un argument fondamental pour la formation de la nation moderne. Ces questions font l'objet de nouveaux débats dans les études sur le baroque et l'art en NouvelleEspagne (GARCÍA CANCLINI, 1988 ; ECHEVERRÍA, 1998 ; voir aussi KATZEW, 2004).

5. «... los usos y los modos colectivos de percepción y la codificación simbólica han cambiado. En términos estructurales la plaza central del centro histórico tiene que competir con las construcciones suburbanas de una aglomerada y segregada megalópolis de 20 millones de habitantes " (KRIEGER, 2011, p. 401-417).

6. L'étude de Cristóbal Andrés Jácome examine le pouvoir de la photographie en tant qu'élément fondamental de l'imaginaire architectural et se clôture sur la tour Insignia.

7. «... una aritmética alarmante [...] un Estado débil y fallido ", (What else could..., 2009, p. 16).

8. En 2010, le département d'histoire de l'art de la Universidad Nacional Autónoma de México a organisé avec des doctorants et des étudiants une exposition intitulée Tiempos Violentos, qui s'est tenue à l'Americas Society, à New York (Tiempos Violentos..., 2010).

9. Bien que Paz ne mentionne pas Chavero dans "Crítica de la Pirámide", il se réfère à la fascination pour les Aztèques comme symptomatique d'une forme de gouvernement autoritariste qui n'a pas changé avec la Révolution mexicaine (PAZ, 1970).

10. "Un edificio que en sus perfiles y composición caracteriza la arquitectura de las razas más civilizadas de México " (Tenorio, 1998, p. 9).

11. «... La figura oscura del indígena entra a la pintura culta, la de la Academia, por un rincón del cuadro y en sumisa actitud o de rodillas. Aparece, en 1850, cuando el pintor Juan Cordero lo hace tema de su cuadro titulado Colón ante los reyes católicos. Como el argumento del cuadro es la presentación de los nativos del nuevo mundo a
Fernando e Isabel, estos en actitud reverente. Dos hombres fuertes y morenos y una bella mujer alejada en cierta medida de los cánones del idealismo clasicista, ya que las facciones de su rostro son las de una mestiza, se inclinan ante sus majestades ofreciendo en un cofre y en una charola, los tesoros de su tierra perdida ", (RODRÍGUEZ PRAMPOLINI, 1988, p. 205).

12. "los caracteres de una cultura mexicana ", (BRADING, 2002b, p. 7).

13. "In these days of Occupy Wall Street, I think of the same stratification revealed in Rivera's work" (conférence de presse de Glenn Lowry, 12 novembre 2011).

14. L'image peut être consultée à l'adresse suivante : http://noesfecalandia.blogspot.fr/2012/01/monumentolos-muertos-de-la-guerra-de.html. 


\section{Bibliographie}

- 1910.., 1991 : 1910, El arte en un año decisivo : la exposición de artistas mexicanos, (cat. expo., Mexico, Museo Nacional de Arte, 1991), Mexico, 1991.

- ACEVEDo, 2001-2004 : Esther Acevedo éd., Hacia otra historia del arte en México: I, de la Estructura Colonial a la exigencia nacional (1780-1860), Mexico, 2001 ; II, La amplitud del modernismo y la modernidad (1861-1920), Mexico, 2002 ; III, La fabricación del arte nacional a debate (1920-1950), Mexico, 2003 ; IV, Disolvencias (19602000), Mexico, 2004.

- ACEVEdo, 2003 : Esther Acevedo, "Los comienzos de una historia laica en imágenes ", dans Los pinceles..., 2003b, p. 34-53. - ANDERSON, 1983 : Benedict Anderson, Imagined Communities: Reflections on the Origin and Spread of Nationalism, Londres, 1983.

- AzUela, 2005 : Alicia Azuela de la Cueva, Arte y Poder: renacimiento artístico y revolución social México, 1910-1945, Zamora/ Mexico, 2005.

- BARAJAS, 2011 : Rafael Barajas, " Caricature and Revolution in Mexico ", dans The Journal of Decorative and Propaganda Arts, 26, 2011, p. 80-101.

- BARTRA, 1981 : Roger Bartra, Las redes imaginarias del poder político, Mexico, 1981. - BARTRA, 1989 : Roger Bartra, "La crisis del nacionalismo en Mexico ", dans Revista Mexicana de Sociología, 3, juilletseptembre 1989, p. 191-226.

- BARTRA, (1999) 2002a : Roger Bartra, Blood, Ink and Culture: Miseries and Splendors of the Post-Mexican Condition, Durham, 2002 [éd. orig. : La sangre y la tinta: ensayos sobre la condición postmexicana, Mexico, 1999].

- BARTRA, 2002b : Roger Bartra, Anatomía del mexicano, Mexico, 2002.

- BARTRA, (1987) 2005: Roger Bartra, La jaula de la melancolía: identidad y metamorfosis del mexicano, Mexico, 2005.

- Benítez DueÑas, 2006 : Issa María Benítez Dueñas, " La historia perdida del arte en México ", dans Curare, 27, juilletdécembre 2006, p. 65-74.

- BENJAMIN, 2000 : Thomas Benjamin, La Revolución: Mexico's Great Revolution as Memory, Myth, and History, Austin, 2000.

- BERMAN, 1982 : Marshall Berman, All that is Solid Melts into Air: The Experience of Modernity, New York, 1982.

- BeRnAL, 1979 : Ignacio Bernal, Historia de la arqueología en México, Mexico, 1979.

- BHABHA, 1990 : Homi K. Bhabha éd., Nation and Narration, Londres/New York, 1990.
- BHABHA, 1995 : Homi K. Bhabha, « Dissemination: Time, Narrative, and the Margins of the Modern Nation ", dans Bill Ashcroft, Gareth Griffiths, Helen Tiffin éd., The Post Colonial Studies Reader, Londres/New York, 1995, p. 176-178.

- BRADING, (1980) 1988 : David A. Brading, Los orígenes del nacionalismo mexicano, Mexico, (1980) 1988.

- BRADING, 2002a : David A. Brading, La virgen de Guadalupe: imagen y tradición, Mexico, 2002.

- BRADING, 2002b : David A. Brading, Octavio Paz y la poética de la historia mexicana Mexico, 2002.

- BRAding, 2004 : David A. Brading, Mito y profecía en la historia de México, Mexico, 2004.

- Braun, 1993 : Bárbara Braun, PreColumbian Art and the Post-Columbian World: Ancient American Sources of Modern Art, New York, 1993.

- Brenner, 1983 : Anita Brenner, Ídolos tras los altares, Mexico, 1983.

- BRETON, 1939 : André Breton, "Souvenirs du Mexique ", dans Minotaure, 12/13, mai 1939, p. 31-52.

- CAplow, 2007 : Deborah Caplow, Leopoldo Méndez: Revolutionary Art and the Mexican Print, Austin, 2007.

- CARdozA y ARAgón, 1940 : Luis Cardoza y Aragón, La nube y el reloj: pintura mexicana contemporánea, Mexico, 1940.

- CARdozA y ARAgón et al., 1983 : Luis Cardoza y Aragón et al., Orozco: una relectura, Mexico, 1983.

- Cetto, 2011 : Max Cetto, La arquitectura moderna en México, Mexico, 2011.

- Charlot, 1985 : Jean Charlot, El renacimiento del muralismo mexicano, 1920 1925, Mexico, 1985.

- CLARK, 1975 : Timothy J. Clark, Image of the People: Gustave Courbet and the Second French Republic, 1848-1851, Londres, 1975. - Coleby, 1985 : Nicole Coleby, La construcción de una estética: el Ateneo de la Juventud, Vasconcelos y la primera etapa de la pintura mural posrevolucionaria, 1921-1924, thèse, Universidad Nacional Autónoma de Mexico, 1985.

- CORDERO REIMAN, 2001 : Karen Cordero Reiman, " Lecturas de forma, formas de lectura: las aportaciones teóricas de George Kubler y el estudio del arte en México ", dans EDER, 2001a, p. 64-89.

- Cordero Reiman, 2002 : Karen Cordero Reiman, "La invención del arte popular y la construcción de la cultura visual moderna en México ", dans ACEVEDO, 2003, p. 67-90.
- Cosío Villegas, 1976 : Daniel Cosío Villegas, El sistema político mexicano, Mexico, 1976.

- Couto, 1995 : José Bernardo Couto, Diálogos sobre la historia de la pintura en México, Mexico, 1995.

- CuAdriello, 2001 : Jaime Cuadriello Aguilar, " Los umbrales de la nación y la modernidad de sus artes: criollismo, Ilustración y academia ", dans ACEVEDO, 2001, p. 17-35.

- CuAdRIEllo, 2002 : Jaime Cuadriello Aguilar, El divino pintor: la creación de María de Guadalupe en el taller celestial, Mexico, 2002.

- CUADRIELlo, 2004 : Jaime Cuadriello Aguilar, Zodiaco Mariano: 250 años de la declaración de María de Guadalupe como patrona de México, Mexico, 2004.

- Curiel, GonzÁlez Mello, GutiérRez, 1994 : Gustavo Curiel, Renato González Mello, Juana Gutiérrez Haces, Arte, historia e identidad en América Latina: Visiones comparativas, (colloque, Mexico, 1994), Mexico, 1994.

- CURTIS, 1991 : William Curtis, " Paisaje mítico: la arquitectura moderna y el pasado mexicano ", dans Hechizo de Oaxaca, Monterrey, 1991.

- DeBroise, 1983 : Olivier Debroise, Figuras en el trópico: plástica mexicana, 19201940, Barcelone, 1983.

- Debroise, 1994 : Olivier Debroise, Fuga mexicana: un recorrido por la fotografía en México, Mexico, 1994.

- Debroise et al., 1996 : Olivier Debroise et al., Otras rutas hacia Siqueiros, (colloque, Mexico, 1996), Mexico, 1996.

- Diego Rivera..., 2011 : Diego Rivera: Murals for The Museum of Modern Art, Leah Dickerman, Anna Indych-López éd., (cat. expo., New York, The Museum of Modern Art, 2012), New York, 2011.

- Dos PAssos, 1927 : John Dos Passos, "Paint the Revolution ", dans New Masses, 15, 1927.

- Dovey, 1999 : Kim Dovey, Framing Places: Mediating Power in Built Form, Londres, 1999.

- ECHEVERRÍA, 1998 : Bolívar Echeverría, La modernidad de lo barroco, Mexico, 1998. - Echeverría, 2007 : Bolívar Echeverría, "El guadalupanismo y el ethos barroco en América ", issue du colloque "Moving Worlds of the Baroque", (colloque, Toronto, 2007), disponible en ligne sur www.bolivare.unam.mx/ ensayos/Guadalupanismo $\% 20$ y $\% 20$ barroco.pdf. 
- EDER, 2000 : Rita Eder, « El muralismo mexicano: modernismo y modernidad ", dans FERNÁNDEZ, NOELLE, 1998, p. 365-376. - EDER, 2001a : Rita Eder éd., El arte en México: autores, temas y problemas, Mexico, 2001.

- EDER, 2001b : Rita Eder, " Modernismo, modernidad, modernización: piezas para armar una historiografía del nacionalismo cultural mexicano ", dans EDER 2001a, p. 341-372.

- EDER, 2006 : Rita Eder, " Eternal Mexico: Between Nationalism and Globalization ", dans John Onians éd., Compression vs. Expression, Williamstown/New Haven, 2006, p. 109-130.

- EDER, 2007 : Rita Eder, « El muralismo mexicano. Más allá de la ideología: hermetismo y modernidad ", dans Gabriela Siracrusano éd., Las tretas de lo visible, Buenos Aires, 2007, p. 109-130.

- EDER, 2010 : Rita Eder, Tiempo de fractura: el arte contemporáneo en el museo de arte durante la gestión de Helen Escobedo (1982-1984), Mexico, 2010.

- EDER, 2011 : Rita Eder, "Tolomeo y Copérnico en el Nuevo Mundo. Juan O'Gorman y el muro sur de la Biblioteca Central en Ciudad Universitaria ", dans Anales del Instituto de Investigaciones Estéticas, 33/98, 2011, p. 137-173.

- EDER, 2012 : Rita Eder, «Benjamin Peret and Paul Westheim: surrealism and other genealogies in the land of the Aztecs ", dans Dawn Ades, Rita Eder, Gabriela Speranza éd., Surrealism in Latin America: Vivísimo Muerto, Los Angeles, 2012.

- El corazón sangrante, 1991 : El corazón sangrante $=$ The Bleeding Heart, Olivier Debroise, Elisabeth Sussman, Matthew Teitelbaum éd., (cat. expo., Houston, Contemporary Arts Museum et autres lieux, 1991-1993), Boston/Seattle, 1991.

- Elderfield, 2006 : John Elderfield, Manet and the Execution of Maximilian, New York, 2006.

- FeLL, 1989 : Claude Fell, José Vasconcelos: Los años del aguila, 1920-1925, Mexico, 1989. - FERnÁNDEZ (Justino), (1952) 1983 : Justino Fernández, Arte moderno y contemporáneo de México, Mexico, (1952) 1983.

- Fernández (Justino), 1962 : Justino Fernández, El hombre: estética del arte moderno y contemporáneo, Mexico, 1962.

- Fernández (Justino), 1967 : Justino Fernández, El arte del siglo XIX en México, Mexico, 1967.

- Fernández (Justino), 1972 : Justino Fernández, Estética del arte mexicano, Mexico, 1972.
- FERNÁNDEZ (María Auxiliadora), 1993 : María Auxiliadora Fernández, The Representation of National Identity in Mexican Architecture: Two Case Studies (1680 and 1889), thèse, Columbia University, 1993.

- Fernández, Noelle, 1998 : Martha Fernández, Louise Noelle éd., Estudios sobre arte: setenta años del Instituto de Investigaciones Estéticas, Mexico, 1998.

- FlorescAno, 1995 : Enrique Florescano éd., Mitos mexicanos, Mexico, 1995.

- Gallagher, Greenblatt, 2000 : Catherine Gallagher, Stephen Greenblatt, Practicing New Historicism, Chicago/ Londres, 2000.

- GALlO, 2005 : Rubén Gallo, Mexican Modernity: The Avant-Garde and the Technological Revolutuion, Cambridge, 2005. - GamboA, 1953 : Fernando Gamboa, "Introduction", dans Mexican Art..., 1953, p. 64.

- GAmio, 1915 : Manuel Gamio, "El concepto de arte prehispánico ", dans Revista de Revistas, 11 juillet 1915.

- GAmio, (1916) 1992 : Manuel Gamio, Forjando patria, Mexico, (1916) 1992.

- GAmio, 1935 : Manuel Gamio, Hacia un México nuevo: problemas sociales, Mexico, 1935.

- GAMIo, 1986 : Manuel Gamio, Arqueología e indigenismo, Mexico, 1986.

- GARCía CANCLINI, 1988 : Néstor García Canclini, Culturas híbridas: estrategias para entrar y salir de la modernidad. Mexico, 1988.

- García de Germenos, 1991 : Pilar García de Germenos, "Exposición de los artistas mexicanos de 1910 ", dans 1910..., 1991, p. 33-60.

- GARCía PONCE, 1968 : Juan García Ponce, La aparición de lo invisible, México, 1968.

- GARCía Riera, 1987 : Emilio García Riera, Emilio Fernández, 1904-1986, Guadalajara, 1987.

- GARduño, 2002 : Ana Garduño, "Hecho en México ", dans Luna Córnea, 23, 2002, p. 155-160.

- GARduño, 2009a : Ana Garduño, El poder del coleccionismo de arte: Alvar Carrillo Gil, (Colección Posgrado, 38), Mexico, 2009.

- Garduño, 2009b : Ana Garduño, "Fernando Gamboa. El curador de la Guerra Fría ", dans Fernando Gamboa: el arte del riesgo, (cat. expo., Mexico, $\mathrm{Mu}$ seo Mural Diego Rivera, 2009), Mexico, 2009, p. 17-65.

- Gellner, 1988 : Ernest Gellner, $\mathrm{Na}$ ciones y Nacionalismo, Madrid, 1988.
- GLUSKER, 1998 : Susannah Glusker, Anita Brenner: A Mind of her Own, Austin, 1998. - Good, 2001 : Carl Good, John V. Waldron, éd., The Effects of the Nation: Mexican Art in an Age of Globalization, Philadelphia, 2001.

- GonzÁlez 1980 : Luis González, « De la múltiple utilización de la Historia ", dans Carlos Pereyra et al., ¿Historia para qué?, Mexico, 1980.

- GonzÁlez Mello, 2002 : Renato González Mello, "El canon liberal ", dans Curare, 18-19, 2001-2002.

- GonzÁlez Mello, 2003 : Renato González Mello, " Los pinceles del siglo XX. Arqueología del régimen ", dans Los pinceles..., 2003a, p. 17-36.

- GonzÁlez Mello, 2008 : Renato González Mello, La máquina de pintar, Mexico, 2008.

- GORI, ESCOBEDO, 1988 : Paulo Gori, Helen Escobedo éd., Mexican monuments: Strange Encounters, New York, 1988.

- GROYS, 2008 : Boris Groys, Art Power, Cambridge, 2008.

- GRUZINSKI, (1990) 1994 : Serge Gruzinski, La guerra de las imágenes: de Cristóbal Colón a Blade Runner (1942-2019), Mexico, 1994 [éd. orig. : La Guerre des images : de Christophe Colomb à Blade Runner (1492-2019), Paris, 1990].

- GRUZINSKI, 2007 : Serge Gruzinski, El pensamiento mestizo: cultura amerindia $y$ civilización del renacimiento, Mexico, 2007. - GutiérRez HACES, 2001 : Juana Gutiérrez Haces, "Algunas consideraciones sobre el término estilo en la historiografía del arte virreinal mexicano ", dans EDER, 200la, p. 90-193.

- GUTIÉRREZ ViÑUALES, 2003 : Rodrigo Gutiérrez Viñuales, « El papel de las artes en la construcción de las identidades nacionales en Iberoamérica ", dans Historia Mexicana, 53/2, 210, 2003, p. 341-390.

- HABERMAS, 1974 : Jürgen Habermas, "On Social Identity ", dans Telos, 19. printemps 1974, p. 91-103.

- Hernández Flores, 2012 : Fabiola Hernández Flores, Construcción de un testigo: biografía cultural de la torre latinoamericana, thèse, Universidad Nacional Autónoma de México, 2012.

- Hers, 2001 : Marie-Areti Hers, "Manuel Gamio y los estudios sobre arte prehispánico : contradicciones nacionalistas ", dans EDER, 2001a, p. 29-63.

- Hershrield, 2008 : Joanne Hershfield, Imagining la Chica Moderna: Women, $\mathrm{Na}$ tion, and Visual Culture in Mexico, $1917-$ 1936, Durham, 2008. 
- HURLbURT, 1989 : Laurance P. Hurlburt, The Mexican Muralists in the United States, Albuquerque, 1989.

- INDICH-LOPEZ, 2009 : Anna IndichLopez, Muralism Without Walls: Rivera, Siqueiros, Orozco in the United States, $1927-$ 1940, Pittsburgh, 2009.

- JÁCOME, 2009 : Cristóbal Andrés Jácome, "Las construcciones de la imagen. La serie del Conjunto Urbano Nonoalco-Tlatelolco de Armando Salas Portugal ", dans Anales del Instituto de Investigaciones Estéticas, 31/95, automne 2009, p. 85-118.

- KARETNIKOVA, 1991 : Inga Karetnikova, Mexico According to Eisenstein, Albuquerque, 1991.

- KAtZew, 2004 : Ilona Katzew, La pintura de castas: representaciones raciales en México del siglo XVIII, Madrid, 2004.

- KATZMAN, 1963 : Israel Katzman, La arquitectura contemporánea mexicana: precedentes y desarrollo, Mexico, 1963.

- KNIGHT, 1991 : Alan Knight, "Intellectuals in the Mexican Revolution ", dans Roderic A. Camp, Charles Hale, Josefina Zoraida Vázquez éd., Los intelectuales y el poder en Mexico, Mexico, 1991, p. 141-172. - KNIGHT, 1994 : Alan Knight, « Popular Culture and Revolutionary State in Mexico 1910-1940", dans Hispanic American Historical Review, 74/3, 1994.

- KRIEGER, 2011 : Peter Krieger, « Body, Building, City, and Environment: Iconography in the Mexican Megalopolis ", dans Udo J. Hebel, Christopher Wagner éd., Pictorial Cultures and Political Iconographies: Approaches, Perspectives, Case Studies from Europe and America, Berlin/New York, 2011, p. 401-418.

- Kubler, 1977 : George Kubler, "Renaissance and Disjunction in the Art of Mesoamerica Antiquity ", dans Via, 3, juillet 1977, p. 31-39.

- La era..., 2007 : La era de la discrepancia: arte y cultura visual en México, 1968-1997, Olivier Debroise éd., (cat. expo., Mexico, Museo Universitario de Ciencias y Artes, 2007), Mexico, 2007.

- LAFAYe, (1977) 2002 : Jaques Lafaye, Quetzalcoatl y Guadalupe: la formación de la conciencia nacional de México, préface d'Octavio Paz, Mexico, (1977) 2002.

- LeMPÉRIÈRE, 1994 : Annick Lempérière, " D'un centenaire de l'Indépendance à l'autre (1910-1921). L'invention de la mémoire culturelle du Mexique contemporain ", dans François-Xavier Guerra éd., Mémoires en devenir : Amérique latine $X V I^{e}-X X^{e}$ siècle, (colloque, Paris, 1992), Bordeaux, 1994, p. 269-292. - LempérIÈRE, 1994 : Annick Lempérière, " La formación de las elites liberales en el México del siglo Xx ", dans Secuencia, 30, septembre-décembre 1994, p. 57-94.

- Lemus, 2011 : Rafael Lemus, "Diego Rivera en Occupy Wall Street ", dans Reforma, 24 novembre 2011.

- LERNER, 2011 la : Jesse Lerner, « Exiles at Home. Constructing Los Angeles and Mexico City in Photography and Film ", dans $M E X / L . A \ldots ., 2011$, p. 58-69.

- LERNER, $2011 \mathrm{lb}$ : Jesse Lerner, The Maya of Modernism: Art, Architecture and Film, Albuquerque, 2011.

- LOMBARDO DE RUíz, 1994 : Sonia Lombardo de Ruíz, El pasado prehispánico en la cultura nacional (memoria hemerográfica 1877-1911), 2 vol., Mexico, 1994.

- LóPEz, 2010 : Rick A. López, Crafting Mexico: Intellectuals, Artisans, and the State After the Revolution, Durham, 2010.

- Los pinceles..., 2000 : Los pinceles de la historia: de la patria criolla a la nación mexicana 1750-1860, Jaime Soler Frost éd., (cat. expo., Mexico, Museo Nacional de Arte, 2000), Mexico, 2000.

- Los pinceles ..., 2003a : Los pinceles de la historia: la arqueología del régimen, 19101955, Jaime Soler Frost, Esther Acevedo, éd., (cat. expo., Mexico, Museo Nacional de Arte, 2003-2004), Mexico, 2003.

- Los pinceles..., 2003b : Los pinceles de la historia: la fabricación del Estado, 1864-1910, Fausto Ramírez, Esther Acevedo éd., (cat. expo., Mexico, Museo Nacional de Arte, 2003-2004), Mexico, 2003.

- Los sueños..., 2011 : Los sueños de una nación: un año después 2011, (cat. expo., Mexico, Museo Nacional de Arte, 2011 2012), Mexico, 2011.

- LUCK, 2009 : Elaine Luck, " Museums and the Narrative Representation of the Nation : Mexico's Museo Nacional de Arte ", dans MHRA: Working Papers in the Humanities, 4, 2009, p. 34-42 (publié en ligne : www.mhra.org.uk/ojs/index.php/ wph/article/view/74/72).

- LYOTARD, (1979) 1984 : Jean-François Lyotard, The Post Modern Condition: A Report on Knowledge, Minneapolis, 1984 [éd. orig. : La condition postmoderne : rapport sur le savoir, Paris, 1979].

- Matos Moctezuma, 1994 : Eduardo Matos Moctezuma, The Great Temple of the Aztecs, Londres, 1994.
- Medin, 1991 : Tzvi Medin, El sexenio alemanista: ideología y praxis política de Miguel Alemán, Mexico, 1991.

- Medina, 2011 : Cuauhtémoc Medina,

"Lo contrario es verdad ", dans MEX/ L.A..., 2011, p. 118-120.

-MEX/L.A..., 2011 : MEX/L.A. «Mexican " Modernism(s) in Los Angeles 19301985, Selene Preciado éd., (cat. expo., Los Angeles, Museum of Latin American Art, 2011-2012), Ostfildern, 2011.

- Mexican Art..., 1953 : Mexican Art from 1500 B.C. to the Present Day, (cat. expo., Londres, Tate Gallery, 1953), Londres, 1953.

- México en el mundo..., 1994 : México en el mundo de las colecciones de arte, 7 vol., Mexico, 1994.

- México eterno..., 1999 : México eterno: arte y permanencia, (cat. expo., Mexico, Museo del Palacio de Bella Artes, 1999), Mexico, 1999.

- Mexico..., 1990 : Mexico, Splendors of Thirty Centuries, (cat. expo., Metropolitan Museum of Art/San Antonio, San Antonio Museum of Art/Los Angeles, Los Angeles County Museum of Art, 1990-1991), New York, 1990.

- MichAlsKi, 1998 : Sergiusz Michalski, Public Monuments: Art in Political Bondage 1870-1997, Londres, 1998.

- Miliotes, GonzÁlez Mello, 2002 : Diane H. Miliotes, Renato González Mello éd., José Clemente Orozco in the United States, 1927-1934, New York, 2002.

- Mininan, 1977 : Janet Minihan, The Nationalization of Culture, New York, 1977. - Modernidad..., 1991 : Modernidad y modernización en el arte mexicano, 1920-1960, (cat. expo., Mexico, Museo Nacional de Arte, 1991), Mexico, 1991.

- Molina, 2005: Carlos Molina, "Fernando Gamboa y su particular versión de Mexico ", dans Anales del Instituto de Investigaciones Estéticas, 27/87, 2005, p. 117-143. - Monsiváis, 1983 : Carlos Monsiváis, " La nación de unos cuantos y las esperanzas románticas ", dans José E. Pacheco et al., En torno a la cultura nacional, (SEP, 80), Mexico, 1983, p. 208.

- MONSIVÁIS, 1987 : Carlos Monsiváis, "Muerte y resurrección del nacionalismo mexicano ", dans Nexos, 109, 1987. - MONSIVÁIS, 1988 : Carlos Monsiváis, « El arte y la cultura nacional entre 1910 y 1930 ", dans SCHAVELZón, 1988a, p. 301-305.

- MonsivÁis, 2010 : Carlos Monsiváis, La cultura mexicana en el siglo XX, Mexico, 2010. - Montalvo, 1986 : Enrique Montalvo, El nacionalismo contra la Nación, Mexico, 1986. 
- Moreno Villa, 1948 : José Moreno Villa, Lo mexicano en las artes plásticas, Mexico, 1948.

- MrAz, 2009 : John Mraz, Looking for Mexico: Modern Visual Culture and National Identity, Durham, 2009.

- Mumford, 1934 : Lewis Mumford, "Orozco in New England", dans The New Republic, 10 octobre 1934.

- NibLo, 2008 : Stephen R. Niblo, México en los cuarenta: modernidad y corrupción, Mexico, 2008.

- Noble, 2005 : Andrea Noble, Mexican National Cinema, Londres, 2005.

- Notimex, 2011 : Notimex, "Luego de 80 años la crítica social de Rivera sigue vigente, subraya titular del MoMA ", dans La Jornada, 9 novembre 2011.

- O'GORMAn, 1998 : Edmundo O'Gorman, "El arte o de la monstruosidad", dans FERNÁNDEZ, NOELLE, 1998, p. 471-476. - Oles, 1993 : James Oles, South of the Border: Mexico in the American Imagination 1914-1947, Washington/Londres, 1993.

- OLes, 1998 : James Oles, "La nueva fotografía y Cementos Tolteca: una alianza utópica ", dans María Casanova éd., Mexicana: fotografía moderna en Mexico, 1923-1940, Valence, 1998.

- OLES, 2011 : James Oles, "Industrial Landscapes in Modern Mexican Art ", dans The Journal of Decorative and Propaganda Arts, 26, 2011, p. 128-159.

- OWEN, 2009 : Graham Owen, Architecture, Ethics and Globalization, Londres, 2009.

- PAgden, 1987 : Anthony Pagden, "Identity Formation in Spanish America ", dans Nicholas Canny, Anthony Pagden éd., Colonial Identity in the Atlantic World, Princeton, 1987, p. 15-50.

- PAz, (1950) 1981 : Octavio Paz, El laberinto de la soledad, Mexico, (1950) 1981. - PAz, 1970 : Octavio Paz, Posdata, Mexico, 1970.

- PAz, 1979 : Octavio Paz, México en la obra de Octavio Paz, Mexico, 1979.

- PAz, (1979) 1981 : Octavio Paz, El ogro filantrópico: historia y política, 1971-1978, Barcelone/Caracas, (1979) 1981.

- PAz, 1981 : Octavio Paz, El laberinto de la soledad, Postdata, Vuelta a El laberinto de la soledad, Mexico, 1981.

- PEÑA, 2005-2006 : Araujo Peña et al., " El culto a la Santa Muerte: un estudio descriptivo ", dans Cognoscere Complexus, 1, 1/1, 2005-2006 (publié en ligne : www.udlondres.com/revista_psicologia/ articulos/stamuerte.htm).
- PÉREZ MONTFORT, 1994 : Ricardo Pérez Montfort, "Indigenismo, hispanismo y panamericanismo en la cultura popular mexicana de 1920 a 1940 ", dans Roberto Blancarte éd., Cultura e identidad nacional, Mexico, 1994.

- PÉREZ MONTFORT, 2007 : Ricardo Pérez Montfort, Expresiones populares y estereotipos culturales en México. Siglos XIX Y XX, Diez ensayos, Mexico, 2007.

- Pérez Vejo, 2001 : Tomás Pérez Vejo, "Pintura de historia e imaginario nacional: el pasado en imágenes ", dans Historia y grafía, 16, 2001, p. 73-110.

- Pi-Suñer Llorens, 2001 : Antonia Pi-Suñer Llorens éd., En busca de un discurso integrador de la nación, 1848-1884, Mexico, 2001.

- RAMíRez, 1983 : Fausto Ramírez, " Artistas e iniciados en la obra mural de Orozco ", dans CARDOZA Y ARAGÓN et al., 1983, p. 61-102.

- RAMíRez, 1988 : Fausto Ramírez, " Dioses, héroes y reyes mexicanos en París, 1889 ", dans Historia, leyendas y mitos de México, su expresión en el arte, (colloque, Mexico, 1988), Mexico, 1988, p. 201-253.

- RAmíRez, 1995a : Fausto Ramírez, "A río revuelto. Una alegoría de la violencia social durante el alemanismo", dans Arturo Pascual Soto éd., Arte y Violencia, (colloque, Mexico, 1995), Mexico, 1995, p. 217-236.

- RAMÍREZ, 1995b : Fausto Ramírez, « Entre la alegoría y la crónica visual: las modalidades estilísticas del Segundo Imperio ", dans Testimonios artísticos..., 1995, p. 20-22. - RAmírez, 2000 : Fausto Ramírez, " La historia disputada de los orígenes de la nación y sus recreaciones pictóricas a mediados del siglo XIX ", dans Los pinceles..., 2000, p. 231-248.

- RAMíREz, 2003 : Fausto Ramírez, "México a través de los siglos (18811910): la pintura de historia durante el porfiriato ", dans Los pinceles..., 2003b, p. 11-143.

- RAMírez, 2008 : Fausto Ramírez, Modernización y modernismo en el arte mexicano, Mexico, 2008.

- RAmírez, 2009 : Fausto Ramírez, "Cinco interpretaciones de la identidad nacional en la plástica mexicana del siglo XIX (1859-1887) ", dans ARBOR, Ciencia, Pensamiento y Cultura, 185/740, novembre-décembre 2009, p. 1169 1184 (publié en ligne : http://arbor. revistas.csic.es/index.php/arbor/article/ view/387/388).
- RAMOS, (1934) 1984 : Samuel Ramos, El perfil del hombre y la cultura en México, Mexico, (1934) 1984.

- RAmos, 1983 : Samuel Ramos, "La cultura criolla ", dans Contemporáneos, 4 , 11/38-39, juillet-août 1931, Mexico, 1983. - Reyes PAlma, 1988 : Francisco Reyes Palma, " 50 años de artes plásticas y política en México (1934-1984)", dans Plural, 200, mai 1988, p. 43.

- Reyes Palma, 1994 : Francisco Reyes Palma, "La LEAR y su revista de frente cultural ", dans Frente a Frente, Mexico, 1994.

- Reyes Palma, 2006 : Francisco Reyes Palma, "La ciudad de la vanguardia. Un recorrido estridentista ", dans Peter Krieger, éd., Megalópolis: la modernización de la ciudad de México en el siglo XX, Mexico, 2006, p. 93-108.

- Riva PAlacio, 1884-1889 : Vicente Riva Palacio, México a través de los siglos: historia general y completa del desenvolvimiento social, político, religioso, militar, artístico, científico y literario de México desde la antigüedad más remota hasta la época actual, Mexico, 1884-1886.

- Rodríguez, 2003 : José Antonio Rodríguez, " El fotomontaje en México : una actitud sociopolítica ", dans Los pinceles..., 2003a, p. 42-46.

- RODRÍGUeZ KURI, 2003 : Ariel Rodríguez Kuri, " Hacia México 68. Pedro Ramírez Vázquez y el proyecto olímpico ", dans Secuencia: revista de historia y ciencias sociales, 56, mai-août 2003, p. 36-73.

- RODRÍGUEZ PRAMPOLINI, 1964 : Ida Rodríguez Prampolini, La crítica de arte en México en el siglo XIX, 3 vol., Mexico, 1964. - RODRÍGUEZ PRAMPOLINI, 1969 : Ida Rodríguez Prampolini, « El nacionalismo en el arte. Consideraciones en vísperas de la Bienal de São Paulo ", dans Excélsior, 26 avril 1969, p. 9.

- Rodríguez PRAMPOLINI, 1988 : Ida Rodríguez Prampolini, "La figura del indio en la pintura del siglo XIX: fondo ideológico ", dans SCHAVELzón, 1988a, p. 201-217.

- RODRÍGUEZ PRAMPOLINI, 2011 : Ida Rodríguez Prampolini, « El culto a Jesús Malverde ", dans Peter Krieger éd., La imagen sagrada y sacralizada, (colloque, Campêche, 2004), México, 2011, p. 323-341.

- Salazar Sotelo, 1983 : Francisco Salazar Sotelo, "Nación y nacionalismo en México ", dans Sociológica: revista del Departamento de Sociología, 21, janvier-avril 1983 (publié en ligne : www.revistasociologica.com.mx/abstract.asp?uid=391). 
- SÁnchez, 2001 : Oswaldo Sánchez, "El cuerpo de la nación. El neomexicanismo : la pulsión homosexual y la desnacionalización ", dans Curare, 17, janvier-juin 2001, p. 136-146.

- SÁnchez ARTECHe, 1998: Alfonso Sánchez Arteche, "Vida secreta de dos cuadros. El descubrimiento del pulque y El senado de Tlaxcala", dans Memoria, 7 , 1998, p. 7-29.

- SCHAVELzón, 1988a : Daniel Schavelzón, éd., La polémica del arte nacional en México (1850-1910), Mexico, 1988.

- SCHAVElzón, 1988b : Daniel Schavelzón, " La arquitectura neoprehispánica tardía (1920-1950) ", dans SCHAVELzóN, 1988a, p. 333-342.

- SCHMILCHUK, 1994 : Graciela Schmilchuk, "El murmullo de la historia ", dans Gustavo Curiel Méndez éd., CuRIEL, GonzÁlez Mello, Gutiérrez, 1994, p. 671-692.

- SHERIDAN, 1999 : Guillermo Sheridan, México en 1932: la polémica nacionalista, (Vida y pensamiento de México), Mexico, 1999.

- Sholette, 2011: Gregory Sholette, Dark Matter: Art and Politics in the Age of Enterprise Culture, Londres, 2011.

- Sin centenario..., 2009 : Sin centenario ni bicentenario : revoluciones alternas, Jaime Cuadriello Aguilar, Iván Acebo Choy éd., (cat. expo., Mexico, Universidad Iberoamericana, 2009), Mexico, 2009.

- TENORIO, 1998 : Mauricio Tenorio, Artilugio de la nación moderna: México en las exposiciones universales, 1880-1930, Mexico, 1998. - Tenorio, 1999 : Mauricio Tenorio, Argucias de la historia: del Siglo XIX, América Latina y Cultura, Barcelone, 1999.

- Tenorio, 2009 : Mauricio Tenorio, Historia y celebración, Barcelone, 2009.
- Testimonios artísticos..., 1995 : Testimonios artísticos de un episodio fugaz (1864-1867), Esther Acevedo, éd., (cat. expo., Mexico, Museo Nacional de Arte, 1995), Mexico, 1995.

- TIBOL, 1974 : Raquel Tibol, Documentación sobre arte mexicano, Mexico, 1974.

- Tiempos Violentos..., 2010 : Tiempos Violentos. reinterpretando la colección del Museo de Arte Carrillo Gil, (cat. expo., Mexico, Museo Carrillo Gil/New York, Americas Society Art Gallery, 2010), Mexico/New York, 2010.

- TORRES, 2007 : Ana Torres, "El imaginario nacional durante la polarización cultural e ideológica. El arte mexicano viaja a París en 1952 ", dans Curare, Mexico, 28, janvier-juin 2007, p. 36-42.

- UMberger, 1987 : Emily Umberger, "Antiques and References to the Past in Aztec Art ", dans Res, 13, printemps 1987, p. 62-105.

- URIBE, 1987 : Eloisa Uribe éd., Y todo... por una nación: historia social de la producción plástica de la ciudad de México, 1761 . 1910, Mexico, 1987.

- VALE, 2008 : Lawrence Vale, Architecture, Power and Nacional Identity, Londres, 2008. - VASCONCELOS, 1995 : José Vasconcelos, La raza cósmica, Mexico, 1995.

- VAsConcelos, (1935) 2000 : José Vasconcelos, Ulises Criollo, Claude Fell éd. Madrid, 2000.

- VÁzQUEZ, 1970 : Josefina Vázquez, Nacionalismo y educación en México, Mexico, 1970.

- Veinte siglos..., 1940 : Veinte siglos de arte mexicano, (cat. expo., New York, Museum of Modern Art, 1940), New York, 1940.

- Velásquez GuAdARRAMA, 1994 : Angélica Velásquez Guadarrama, " La historia patria en el Paseo de la Reforma.
La propuesta de Francisco Sosa y la consolidación del Estado en el porfiriato ", dans Curiel, GonzÁlez Mello, Gutiérrez, 1994, p. 333-344.

- Velásquez Guadarrama, 2001 : Angélica Velásquez Guadarrama, « Las biografías de Manuel G. Revilla y los estudios del arte académico del siglo XIX ", dans EDER, 200la, p. 252-271.

- Villoro, 1950 : Luis Villoro, Los grandes momentos del indigenismo en México, Mexico, 1950.

- Westheim, 1971 : Paul Westheim, La calavera, México, 1971.

- What else could, 2009 : What else could we talk about?, Cuauhtémoc Medina, Teresa Margolles éd., (cat. expo., Venise, $53^{\mathrm{e}}$ Biennale de Venise, Pavillon mexicain, 2009), Barcelone, 2009.

- Widdifield, 1996 : Stacey G. Widdifield, The Embodiment of the Nacional in Late Nineteenth-Century Mexican Painting, Tucson, 1996.

- WidDIFIELD, 2001 : Stacey G. Widdifield éd., Hacia otra historia del arte en México: la amplitud del modernismo y la modernidad (1861-1920), II, Mexico, 2001.

- YBARRA-FRAUSTO, 1990 : Tomas Ybarra-Frausto, "Images of a Community ", dans Eva Sperling Cockcroft, Holly Barnett Sánchez éd., Signs from the Heart: California Chicano Murals, Los Angeles, 1990.

\section{Mots-clés}

imaginaire national, indigénisme

historiographie nationaliste, Mexique, muralisme 